WIDER Working Paper 2018/45

Incentives to labour migration and agricultural productivity

The Bayesian perspective

Marie Albertine Djuikom

April 2018

United Nations University World Institute for Development Economics Research 
Abstract: Understanding how internal labour migration affects the agricultural sector is important for all developing countries whose markets do not work well or are non-existent. In fact, even if the movement out of the agricultural sector can be viewed as a process to reach development for many African countries, this could lead to a negative effect on the rural economy. The availability of labour and the cost of hiring people to work on farms is an example of a problem that farmers may face in the presence of a critical level of labour migration. This paper investigates the effect of internal labour migration on agricultural productivity of rural households in Uganda. Since households select themselves into migration this raises the endogeneity problem. In order to account for the endogeneity of the migration decision and the fact that the effect might be different from one household to another, I model the households' decisions to participate in migration along with their investment in agricultural productivity using the Bayesian treatment analysis. This approach allows me to self-match each household and to estimate a distribution for the counterfactual outcome. The results show that even if on average internal labour migration positively affects agricultural productivity, there are some households for which the effect is negative. Those households for which the effect is negative are mostly small farmers and are therefore more likely to be poor and thus more sensitive to the local price volatility. Moreover, the average effect of the labour migration tends to increase with the likelihood of participating in the internal labour migration. In parallel, I also examine to what extent previous migration rates, widely used in the literature as instrument for the migration decision, are exogenous to the agricultural productivity. It turns out that previous households' decisions to participate in migration are intimately correlated with their current agricultural productivity.

Keywords: labour migration, agriculture, Bayesian treatment analysis, instrumental variables, rural, Uganda

JEL classification: O15, O13, O18, J61, Q12

Acknowledgements: I would like to thank Guy Lacroix, Dominique Van De Walle, Carlos Gradín and Leila Njee Bugha for their helpful comments. I also thank all participants of the WIDER Development Conference on 'Migration and mobility - new frontiers for research and policy', jointly organized with the African Research Universities Alliance (ARUA), on 5-6 October 2017 in Accra, Ghana. My gratitude goes to the UNU-WIDER team who provided me with an excellent working environment at the beginning of this project through their visiting $\mathrm{PhD}$ Fellowship Programmme.

* CRREP, Université Laval, Québec, Canada, email: marie-albertine.djuikom-tamtchouong.1@ulaval.ca.

This study has been prepared within the UNU-WIDER Visiting PhD Fellowship programme.

Copyright (C) The Author 2018

Information and requests: publications@wider.unu.edu

ISSN 1798-7237 ISBN 978-92-9256-487-2 https://doi.org/10.35188/UNU-WIDER/2018/487-2

Typescript prepared by Ans Vehmaanperä.

The United Nations University World Institute for Development Economics Research provides economic analysis and policy advice with the aim of promoting sustainable and equitable development. The Institute began operations in 1985 in Helsinki, Finland, as the first research and training centre of the United Nations University. Today it is a unique blend of think tank, research institute, and UN agency — providing a range of services from policy advice to governments as well as freely available original research.

The Institute is funded through income from an endowment fund with additional contributions to its work programme from Finland, Sweden, and the United Kingdom as well as earmarked contributions for specific projects from a variety of donors.

Katajanokanlaituri 6 B, 00160 Helsinki, Finland

The views expressed in this paper are those of the author(s), and do not necessarily reflect the views of the Institute or the United Nations University, nor the programme/project donors. 
Understanding how internal labour migration affects the agricultural sector is important for all developing countries whose markets don't work well or are non-existent. In fact, even if the movement out of the agricultural sector can be viewed as a process to reach development for many African countries, this could lead to a negative effect on the farmers' activities and thus on the rural economy. The availability of labour and the cost of hiring people to work on farms are examples of problems that farmers may face in the presence of a critical level of labour migration. In addition, farmers are less likely or unable to invest in technologies that allow them to rely less on labour. In Uganda the agricultural sector is highly labour-intensive and it employs about 80 per cent of the active population. Surprisingly, so far there are few empirical studies devoted to the issue (De Brauw, 2010; Mwesigye and Matsumoto, 2016; Mendola, 2008; De Haan, 1999).

From a theoretical point of view, labour migration can have a positive or negative effect on agricultural production (De Brauw, 2010). The effect could be positive if the migrant-sending households can hire individuals on the local labour market to substitute for the migrant. If, on the other hand, the households cannot find a replacement because of the scarcity or the cost of the labour force ${ }^{1}$, labour migration could negatively affect the agricultural production. ${ }^{2}$ For these reasons, the effect of the labour migration is likely to be different across households depending on factors such as the migrant's productivity and the ability of households to adjust their decisions to the local market constraints. It is therefore important to account for this heterogeneity in order to figure out which households are positively or negatively affected by the migration and then to be able to provide relevant policy recommendations for the most vulnerable population.

Unlike the existing literature that assumes that the effect of internal labour migration is homogeneous across households, this study estimates the distribution of the effect of the internal labour migration on the agricultural productivity of households living in the rural areas of Uganda. I use the four survey rounds of the unique nationally representative panel surveys, the Uganda National Panel Survey (UNPS) that started in 2005. To achieve my goal, I estimate simultaneously and over time the households' decisions to invest in agricultural production and to participate in internal labour migration using a Bayesian treatment approach. This approach has been used to allow the heterogeneity of the effect between individuals and to account for the endogeneity of their decision. In fact, Carneiro et al. (2003) use this approach to estimate the distribution of the return to school in terms of earnings for youths in the United States.

Furthermore, I consider that the labour migration decision is a common agreement among household members to send one or more member(s) outside the village (in another district) to find additional sources of income so as to increase household resilience to negative shocks. Indeed, for the households living in the rural areas, the labour migration provides a kind of insurance in times of bad harvest and a source of financial support to smooth household consumption, expand household's business(es), launch a new business, or invest in education. This insurance is even more important for the poorest households in the rural areas of most developing countries such as Uganda, because the access to credit is virtually non-existent without any collateral. Therefore,

1 It can be difficult to find a substitute if the migrant is highly productive, especially so if we consider villages with high migration rates.

$2 \mathrm{My}$ aunt who lives in my village in Cameroon usually says that it becomes more difficult to find people to work on a farm even if you have money to pay for it. 
labour migration is not a unilateral decision taken by one person. Even if a household member can decide to migrate on his own initiative, it is less likely that it will be done without the consent of other household members. Indeed, the loss of available labour to the household directly affects the labour supply in and out of the farm sector of all members left behind, and particularly in farming since the agricultural sector is highly labour-intensive. For instance, Mu and Van de Walle (2011) find that labour migration increases the time that women left behind spend doing domestic and farm work.

In this way, this study is fully integrated into the New Economics Labour Migration (NELM) theory developed by Stark and Bloom (1985) for which the labour migration decision is a common agreement by household members. Using the Bayesian approach, I am able to account for the endogeneity of the migration decision and to estimate an average effect for each household. Moreover, I allow for the selection into migration to depend on households' time-invariant unobserved heterogeneity such as households' willingness to take risks since it is not sure that households participating in internal labour migration will have positive returns from it. These confounders affect both the labour migration decision and the investment in agricultural production. Most studies do not account for the self-selection of households into migration based on their unobserved heterogeneities, which can lead to bias estimations of the impact of labour migration. As a result, this paper thus contributes to the literature by evaluating to what extent this type of selection is related to the effect I attempt to identify and investigates whether the internal labour migration decreases (increases) the agricultural productivity of all households in the rural areas of Uganda. The Bayesian approach has recently been introduced in the treatment analysis and provides, from an implementation point of view, an easier way to account for households' time-invariant fixed effects and to estimate a distribution of the counterfactual outcome for each household.

To sum up, the contribution of this paper is twofold. First, to the best of my knowledge this is the first study that attempts to estimate the causal effect of internal labour migration on households' agricultural productivity in Uganda. Moreover, I go beyond estimating an average effect by estimating the distribution of the effect on households. Second, the methodology used here allows to verify the exclusion assumption on the variables used as instruments to correct for the endogeneity of the participation in labour migration. In fact, it is generally admitted in the literature that the past history of households' participation in internal labour migration only affect the current and future migration participation but not the pattern of the outcome of interest.

I find evidence that the average impact of the internal labour migration on agricultural productivity is positive: labour migration tends to increase the agricultural productivity of households by 44 per cent. This is in line with the NELM theory which argues that the labour migration enables households to invest in the agricultural sector. However, there are some households for whom the effect is negative, about 30 per cent of households participating in migration. These households are mostly small farmers and are therefore more likely to be poor. Furthermore, households with a higher likelihood of participating in migration also have a higher average effect, meaning that households select themselves into migration in order to increase their agricultural productivity. Moreover, my results suggest that previous participation in the internal labour migration violate the Instrumental variable exclusion restriction assumption and thus have to be included in the agricultural productivity equation.

The remainder of this paper is organized as follows. The next section provides a brief review of the literature on internal labour migration in Africa and an overview of the socio-economic environment in Uganda. In section 3, I describe the data and provide a preliminary analysis. Section 4 presents the empirical model and discusses the identification strategy. Section 5 presents the main results and section 6 is the conclusion. 
The incentives for internal labour migration and its (average) effect on the outcomes of the household members left behind as well as on the migrants have not attracted much attention (Garip, 2008; Mendola, 2008; Mu and Van de Walle, 2011; Garlick et al. , 2016; De Haan, 1999; Mwesigye and Matsumoto, 2016; Muto, 2009; Kuhn, 2015; Stack and Taylor, 1991; De Brauw, 2010). Moreover, through the available data it is hard to identify who migrates internally and further to evaluate how important the internal labour migration is in developing countries.

Existing studies reveal that the push factors of the internal labour migration range from the economic costs (household wealth), the household social capital network and relative deprivation, the variation in rainfall, to the increase in the investment in human capital. Furthermore, labour migration enables households to invest in the non-farm activity and in education, acquire new land, improve the health of household members, smooth household consumption and more generally improve the well-being of the household left behind. However, the internal labour migration doesn't lead to a huge transformation in the agricultural sector but helps households to meet their basic needs, and lightly increases agricultural productivity (De Haan, 1999). Based on seven papers investigating the effect of migration on households agricultural production in the rural areas of six developing countries, Davis et al. (2010) find that migration facilitates a transition away from agriculture or leads to less labour-intensive agriculture. Empirical evidence shows that the NELM failed in most cases since the labour migration does not necessarily lead to an investment in the agricultural sector.

Given the expansion of internal labour migration in the developing countries, if migration negatively affects the largest producers, it might be urgent for the government to invest more in their agricultural sector in order to stabilize or even increase the domestic agricultural production. When the domestic production is more volatile, households living in the rural areas whose daily food consumption is intimately related to the local products can see their purchasing power decrease significantly. Meanwhile, many recommendations in terms of development policies have long focused on investment in education and in non-farm sectors as a natural way out of poverty. As a result, from the moment that households are able to have access to capital through migration, they are more likely to invest in non-farm businesses that lead to a decrease in total agricultural production.

The case of Uganda is interesting since its economy is heavily dependent on the agricultural sector. It is an East African country emerging from decades of conflict and security challenges in the Northern part of the country. In 2006, all stakeholders signed a cessation of hostilities agreement. These conflicts have caused a massive displacement of people from the affected areas and delayed their development. However, many people have already returned home and to their day-to-day life. It is then likely that the average agricultural productivity will be lower in this part of the country. Nevertheless, northern Uganda is not the region with the highest rate of migration (labour migration or other). In fact, similarly to central Uganda, only 50 per cent of people who were born in the north continue to live in the north. Besides, this study covers the period 2009-2011 which corresponds to at least three years after the end of the conflicts.

Additionally, less is known about the incentives of internal labour migration and its effects on the well-being of households left behind in Uganda. In fact, most studies devoted to labour migration in Uganda are primarily descriptive. Rutaremwa (2011) and Bukuluki (2015) give the profile of migrants and describe the uses of remittances from both international migration and internal migration in Uganda. Their results show that the remittances are mainly used for school investment, savings and to invest in buildings. Besides, Rutaremwa (2011) points out that 
compared to international migrants, internal migrants come from poorer households and that remittances are lower in value. This implies that the return to internal labour migration in Uganda may not balance the cost in terms of labour loss. Nevertheless, Jagger et al. (2012) find a positive effect of circular migration in the logging business on the households living in the community of origin of migrants. Particularly, their results reveal that migration reduces inequality in the community of origin, yet, the study focuses only on households living in the southwestern part of Uganda. My paper thus fills a gap in the literature by providing evidence of the effect of the internal labour migration using nationally representative data. However, in the rural areas of Uganda, Muto (2009) finds that internal labour migration increases with the household's social network proxied by being a member of the larger ethnic group present in the capital (Kampala).

Moreover, Uganda is one of the poorest countries in Africa with 80 per cent of the population living in rural areas and where the agricultural sector has contributed up to 28.3 per cent of the GDP in 2011 and 25.5 per cent in $2015^{3}$. In addition, Uganda is the country with the highest proportion of its population being aged less than 30 years old; they represent around 78 per cent of the entire population and about half of the population is under 16 years old. Meanwhile, school dropout is a big concern, Ssewamala et al. (2011) report that, in 2007, only one third of children enrolled in the first grade of primary school were likely to participate in the seventh year (last grade of primary school). In fact, as we can see in Figure A2, even though the education level of people aged between 15 and 35 years has increased over time ${ }^{4}$, only 50 per cent of these individuals have actually completed their primary education, which corresponds to seven years of education in the Figure. Along with that, the internal labour migration rate at household level has increased over time. Indeed, the percentage of households involved in migration was 10 per cent in 2005 versus 24 per cent in 2011 and, the share of migrating household members is increasing with the average education level of members living in the same house (Figure A3). As a result, many more Ugandans are involved in labour migration now with the recent boom in educational attainment (Figure A4).

The dataset contains information on the duration of the labour migration and whether the migrants are still considered a household member. In the sample, temporary labour migration accounts for around 95 per cent of the internal labour migration, i.e. when a household member lives away from home for at least three months and is still considered a member of the household and is not a permanent migrant. The average migration duration within each household ranges from three to ten months. Consequently, my focus in this paper is on the temporary internal labour migration.

Furthermore, there is evidence that migrants are more highly educated than non-migrants implying that households participating in labour migration have members with higher ability than nonmigrant households. Figure A1 shows that the agricultural production increases with the household head's years of education and the average years of education among the members of the household. Thus, the existence of unobserved confounders such as ability that is positively correlated with the level of education may affect both the agricultural production decision and incentives to involve in migration. Therefore, the existence of such a confounder can introduce one source of endogeneity of household assignment into labour migration.

Another main source of endogeneity is the social capital network. In developing countries, it is very common for people belonging to the same ethnic group or belonging to the same family

\footnotetext{
${ }^{3}$ Trading economics website: https://tradingeconomics.com/uganda/agriculture-value-added-percent-of-gdp-wbdata.html.

${ }^{4}$ This result might be due to the 'Universal Secondary Education (USE)', implemented by the government in 2007, to make tuition fees free for ordinary secondary schools. Asankha and Takashi (2011) find a positive effect of USE on girls in secondary school enrolment.
} 
(called the 'strong ties') or living in the same village (called the 'weak ties'), to help one another. In the case of migration, a household's social network increases the propensity to participate in migration by reducing the uncertainty surrounding the expected gain from migration and by reducing the monetary costs. For instance, from its social network, a household can get information about job opportunities in the potential destination, a place to live or even a ride to the desired place. The endogeneity comes from selection into social network and the fact that we do not observe the household's social network while it is likely that it affects both the migration decision and the household production. ${ }^{5}$ Furthermore, when the household decides to participate in labour migration, it simultaneously decides the level of agricultural production given the land owned, the labour available (from household members and hired labour) and other inputs. Consequently, the selection into the migration is not exogenous of the agricultural production decision.

\section{Data and preliminary analysis}

This study uses the Uganda National Panel Survey (UNPS) conducted by the Uganda Bureau of Statistics (UBOS) with the technical support of the Government of the Netherlands and the World Bank Group. The units of interest for these surveys are individuals, households, and community/facilities. The surveys cover multiple topics such as health, education, consumption, labour force, etc. with a special module on agricultural activities. This is the first national representative panel data that covers a large number of socio-economic and demographic indicators. Launched in 2009, the surveys are implemented over a 12-month period divided in two visits (over a period of six months each) in order to rule out or at least minimize measurement errors on agricultural inputs and outputs. The first visit is about, among others, inputs and outputs of the last cropping season which could be the short or long season cropping; besides, in the same period, the consumption module is implemented on half of the sample. Four waves implemented in 2009-2010, 2010-2011, 2011-2012 and 2012-2013 are publicly available ${ }^{6}$. Henceforth, each panel wave will be identified by the last year of the corresponding survey.

Initially, 3,220 households have been selected from 7,426 households interviewed in the 20052006 Uganda National Household Survey (UNHS) and tracked and re-interviewed up to the third wave. Thereby, it is possible to connect data from the UNHS to the panel data. At the fourth round, some adjustments have been made to the initial sample. In fact, the households extracted from the Uganda census survey implemented in 2012 have replaced a part of the panel sample. Therefore, the sample has changed significantly, and the sample weights have been corrected. The goal of the sample rotation was to correct for the attrition and random answers that might occur when the households are already used to being interviewed. The average attrition rate at household level is around 17 per cent across waves. This attrition mainly comes from the fact that the new location of some households who have moved is unknown. Since in this study I focus on migration where a household sends a member outside but not the migration for which a household moves, it is less likely that this attrition raises issues of selection bias. Besides, the highest rate of attrition is observed among households living in the urban area and mainly in Kampala while the focus of this paper is on rural households.

\footnotetext{
${ }^{5} \mathrm{It}$ is well documented in the literature how social networks impact the way that people behave.

${ }^{6}$ Data is available on the World Bank website: http://microdata.worldbank.org/index.php/catalog/lsms.
} 
The main goal of the UNPS is to provide reliable national representative data for the experimentation and assessment of the national policies and programs (UBOS 2013). The sample is clustered at the community level and covers all of the four regions and 323 communities of Uganda. In this study, I focus on agricultural households living in rural areas where about 80 per cent of households live. Agricultural households are defined as households with at least one member operating a holding (farming household) or for which the head, reference person or the main earner is economically active in the agricultural sector (see Glossary of Statistical Terms $2007^{7}$ ). In my sample, about 75 per cent of households are actually involved in agricultural activities across waves of survey. Since there are movements in and out of the agricultural sector at the household level and that the panel data is not balanced, the analysis will focus on the balanced sub-sample for which I have information on agricultural productivity for all periods; I will call this sample the sample $A$ throughout this study. The sample of households for which the information on agricultural production is not missing at least for the first round of panel survey is noted Sample $B$.

\subsection{Labour migration prevalence and agricultural productivity}

UNPS provides detailed information that helps define migrants and their profiles. In fact, it is possible to know why a household member was absent during a certain period in the past twelve months, the duration of his absence, the district of destination and so forth. In this paper, I am interested in migration decisions at the household level, that is, I estimate the propensity of a household to get involved in labour migration. Thereby, I identify the migrants-sending household $(\mathrm{HH})$ as a household with at least one member who has spent at least three months outside the household dwelling place in the past twelve months preceding the survey ${ }^{\mathbf{8}}$ and who is still considered a household member. ${ }^{9}$ Moreover, it is common for a migrant to be considered as a household member. This is consistent with the way that I treat the migration decision, that is, migration is a household decision rather than an individual one.

\section{Labour migration prevalence}

With the available information, it is possible to distinguish between labour migration and migration for other economic reasons. I have grouped these two types of migration together as they lead at the end to the same goal, which is to find a job upon arrival at the destination place. For simplicity, I will identify this group of households as labour migrants-sending HHs or simply migrantssending HHs. The data reveal that the migration participation rate among households increased over time from 11.2 per cent in 2006 to 24.6 per cent in 2012. However, it is not possible to know if it is rural-urban or rural-rural or urban-urban migration because only the district of destination is known and unfortunately many districts have both urban and rural areas in Uganda. Most often, migration is from one district to a different district and practically never in the same district.

Migration rates vary across regions with the highest rates in the centre and in the North. Given the long history of instability in the north, the high migration rate can be driven by the less advantaged economic environment and the lack of job opportunities. Moreover, while the migration rate increases over time in the other regions, there is a mitigated pattern in the western part of Uganda. In fact, the migration rate increased from 19 per cent in 2010 to 31 per cent in 2011 and decreased to 25 per cent in 2012. In the meantime, the poverty rate also increased

\footnotetext{
${ }^{7}$ https://definedterm.com/agricultural_household.

${ }^{8}$ A period of three months is the most common in the literature.

${ }^{9}$ That is to still keep the perspective of temporary migration.
} 
between 2010 and 2011 and decreased between 2011 and 2012. On the contrary agricultural production has followed the opposite pattern in the western part by decreasing between 2010 and 2011 and increasing between 2011 and 2012. Therefore, it seems that agricultural production in the west of Uganda is more sensitive to the movement of people. Furthermore, the average duration that migrants spend outside their district is around two and a half months and this duration increases with the years of education of the household head and the average years of education of household members. It is also the case for the share of household members involved in migration. In other words, households where the members are more educated are also more likely to participate in labour migration for a longer period.

Table 1: Migration Rate and agricultural production

\begin{tabular}{|c|c|c|c|c|c|c|c|c|c|}
\hline \multicolumn{3}{|c|}{ Whole Sample } & \multicolumn{5}{|c|}{ Agricultural Households in rural areas } & \multirow[b]{2}{*}{ Northern } & \multirow[b]{2}{*}{ Western } \\
\hline$\overline{\text { Year }}$ & $\overline{\text { All }}$ & Rural & Urban & Sample A & $\begin{array}{r}\text { Sample B } \\
\text { BBple B }\end{array}$ & Central & East & & \\
\hline \multicolumn{10}{|c|}{ Migration rate } \\
\hline 2006 & 11.2 & 10.2 & 14.5 & 10.0 & 10.5 & 10.0 & 9.2 & 7.3 & 15.3 \\
\hline 2010 & 17.8 & 17.1 & 19.9 & 17.7 & 17.7 & 25.3 & 12.8 & 11.5 & 20.5 \\
\hline 2011 & 23.9 & 23.3 & 27.2 & 25.8 & 24.7 & 27.6 & 20.7 & 19.9 & 31.0 \\
\hline 2012 & 24.6 & 24.2 & 26.4 & 26.1 & 26.4 & 36.8 & 21.3 & 26.2 & 25.8 \\
\hline Total & 22.3 & 21.8 & 24.1 & 23.3 & 23.0 & 29.0 & 18.5 & 19.3 & 26.2 \\
\hline \multicolumn{10}{|c|}{ Agricultural production per hectare } \\
\hline 2010 & $4,815.6$ & $5,847.7$ & $1,811.9$ & $7,244.4$ & 7245.2 & $5,966.7$ & $4,336.9$ & $6,289.8$ & $11,291.8$ \\
\hline 2011 & $5,224.3$ & $5,971.8$ & $1,442.2$ & $6,916.5$ & 6277.9 & $5,146.9$ & $7,226.6$ & $4,511.7$ & $7,370.6$ \\
\hline 2012 & $3,709.8$ & $3,901.5$ & $2,873.4$ & $6,519.8$ & 5899.6 & $6,477.7$ & $3,707.0$ & $5,559.0$ & $7,676.1$ \\
\hline Total & $4,582.0$ & $5,218.4$ & $2,041.8$ & $6,916.3$ & 6477.6 & $5,792.6$ & $5,409.5$ & $5,325.9$ & $8,689.3$ \\
\hline $\begin{array}{l}\text { Nb. Obs. } \\
\text { Obs. }\end{array}$ & 2,617 & 2,201 & 768 & 1,4522 & 1,749 & 393 & 493 & 439 & 444 \\
\hline
\end{tabular}

Notes: Percentage is given in each cell. The statistics given by region in the last four columns is computed on the sample $B$. In the sub-table for agricultural production, I have reported the average production per household in kilograms per hectare.

Source: Author's calculations based on UNPS.

In our data, we also have households whose head has migrated permanently for economic or education reasons within the last ten years. This information is sometimes used to capture the migration rate among individuals. To avoid any selection bias due to the household head past migration, in Table A1 we have reported the household labour migration status, as defined in this study, regarding the head's past permanent migration. It emerges that there is no significant difference in the proportion of the head's past permanent migration by household migration status. Therefore, it is less likely that there is selection into the actual migration participation due to the past permanent migration decision of the head. Nevertheless, we introduce this variable as an independent co-variable in migration participation and agricultural production equations.

\section{Agricultural production}

The agricultural production reported in Table 1 is the average production of the main crops planted, that is, production of maize, beans, coffee, peanuts, bananas and potatoes. As we can see, the agricultural production tends to decrease across periods with higher average production in the rural areas. Regarding the distribution by region, the higher level of agricultural production is found in Western Uganda and except for the East, the production decreased between 2010 and 2011 and increased between 2011 and 2012. Despite this upward trend over the last two periods, the level of production in 2012 is still lower than the production in 2010 meaning that the agricultural production has decreased over the period covered by the study. In Eastern Uganda, although we end up with the lowest productivity in $2012(3707.0 \mathrm{~kg} / \mathrm{ha})$, there was an increase of the production 
between 2010 and 2011 (4,336.9 vs 7,226.6 kg/hectares). In addition, the average total area planted per household has also decreased across periods with a large drop between 2011 and 2012, which can explain the lower production in the last period.

It sometimes emerges in the literature that the migration increases land-related conflicts because, due to cultural diversity induced by migration, it may be difficult to resolve conflicts based on customary laws in the absence of formal legislative law. In my sample, about 12.4 per cent of households have reported having a conflict about at least one piece of land they possess; however, the share of households involved in land-related conflicts declined across periods with only 10.5 per cent of households reporting land-related conflicts in 2012. On whether the presence of landrelated conflict can affect household investment in the agricultural sector, I find that households that faced a land-related conflict have lower agricultural productivity in the first two periods, yet in the last period there is no difference in agricultural production. Moreover, the average total area planted by households facing land-related conflicts is even higher.

I also look if the household's social network driven by ethnicity group can help increase the agricultural productivity by providing advice and tips. Figure 4 shows the agricultural productivity given the share of households in the same ethnic group in each district. As we can see, there is a non-linear relationship between the agricultural production and ethnic concentration; the production increases with the size of the ethnic group's social network but after crossing a certain level of ethnic concentration, agricultural productivity tends to decrease.

\subsection{Household profile and migration status}

Table 2 presents some households' characteristics by their labour migration status. It appears that among households participating in labour migration (Migrants-sending HHs), the migration propensity increases between the first and the second quartiles of the wealth distribution of households. ${ }^{10}$ However, from the third quartile of the wealth distribution, the migration propensity starts to decrease. Moreover, by comparing the share of migrants-sending HHs and the share of non-migrants-sending $\mathrm{HHs}$ in each quartile of the wealth distribution it is only for the households in the first and in the last quartiles that I have found a significant difference. In fact, for the households belonging to the first quartile of wealth distribution, the share of migrantssending HHs is significantly lower than the share of non-migrants-sending HHs and, the share of migrants-sending HHs is higher for the households belonging to the fourth quartile. It seems that the monetary cost of labour migration could be a disincentive to participate in migration for the poorest households and, for the households in the middle of the distribution, other important factors affect their decision to participate or not in labour migration. Moreover, the migration rate increases across survey rounds for households belonging to the first quartile of the wealth distribution while it decreases for households in the other quartiles. This suggests that households readjust their migration decision across periods by comparing the cost and the gain obtained from the migration and we expect that if there is any positive net gain, they will be more likely to participate in migration. We can see this evidence for the poorest households since their migration rate increased across periods. Beyond the monetary costs, there are other factors that determine households' labour migration decisions. In fact, migration decisions are intimately related to the household head's characteristics and the composition of the household.

Households headed by a widow or by a polygamous person are more likely to participate in migration. It is also the case with a female or a highly educated household head. In addition, the

${ }^{10}$ Household wealth is measured here by the total expenditures made by household for consumption, education, health, etc. 
households' heads of migrants-sending HHs are slightly older than the heads of non-migrantssending HHs. To investigate to what extent the missing values for a head's education can introduce selection bias, I have computed the percentage of households for which the head's education is missing. It turns out that few if not any migrants-sending HHs have heads with missing value for education, yet, there is a very small share (3 per cent) of household heads for which the head has missing years of education among the non-migrants-sending HHs. Generally, the heads' characteristics for migrants-sending $\mathrm{HHs}$ and non-migrants-sending $\mathrm{HHs}$ do not vary across survey rounds.

Regarding the composition of the households, migrants-sending HHs have larger size households and lower infant-age dependency ratios (share of children aged less than five years old). Besides, the gap of infant-age dependency between migrants-sending HHs and non-migrants-sending $\mathrm{HHs}$ increases across periods, meaning that the gain due to migration may not offset the labour cost when the household has many children aged less than five years old and then needs to readjust their migration decision. I have also reported in this table the average age and the education of individuals who migrate or not within each household. Results reveal that the years of education and age of persons left behind are almost identical within migrants and non-migrants-sending HHs. However, individuals who migrate are in general more educated than those left behind, and the average years of education has increased from one period to another, from around four years in 2010 to seventeen years in 2012 .

In order to see whether ethnic concentration or ethnic diversity constitutes a push or pull factor for migration, I have computed the average share of individuals in the same ethnic group of each household and it comes out that migrants-sending HHs have a slightly smaller ethnic network than non-migrant-sending HHs. I also look at the agricultural productivity and find that migrantssending HHs have a higher average agricultural productivity than non-migrants-sending HHs. This supports the NELM theory that the labour migration might actually help invest more in the agricultural sector. In addition, migrants-sending $\mathrm{HH}$ planted in larger areas and harvested many more crops than non-migrants-sending HHs. 
Table 2: Households Profile depending on their migration status

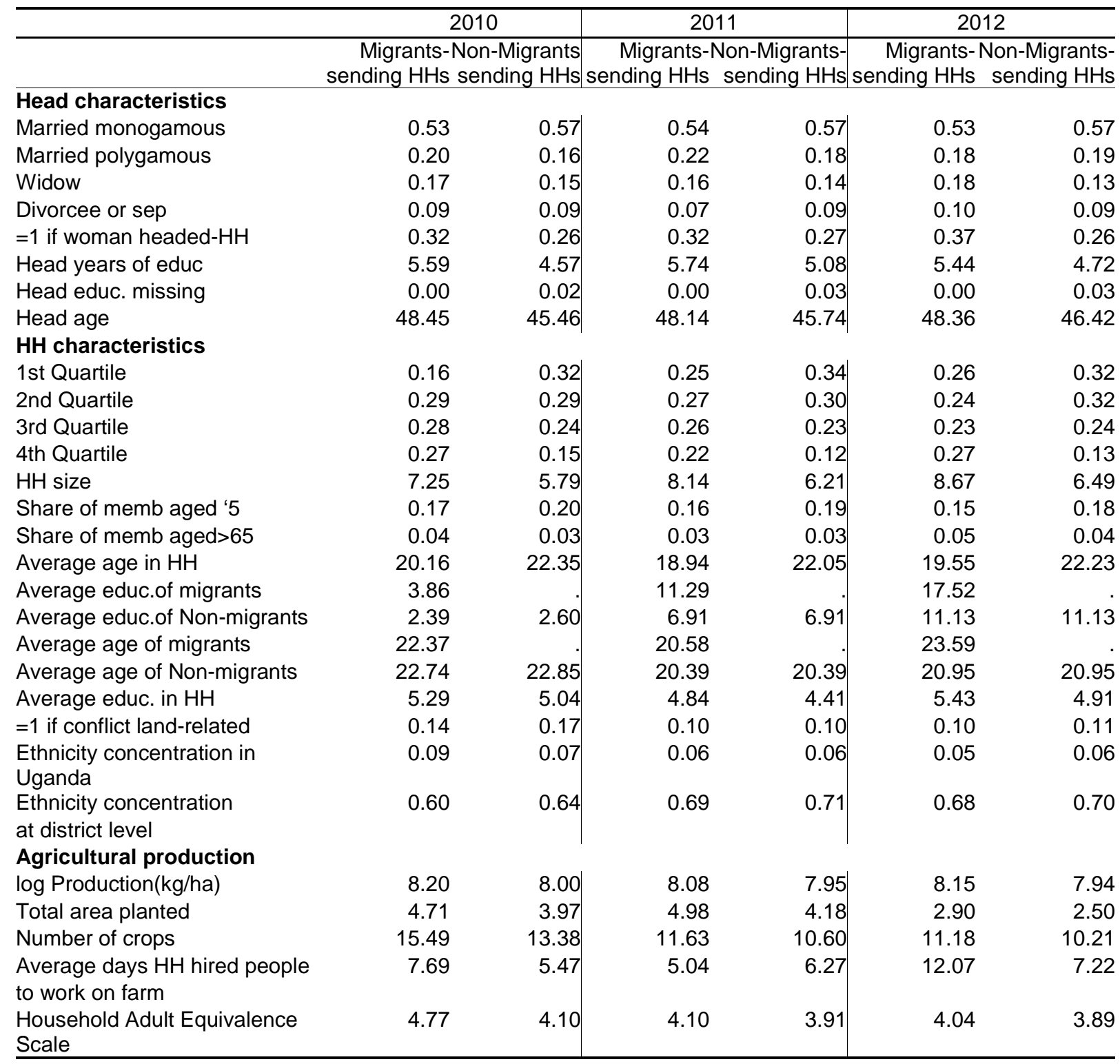

Source: Author's calculations based on UNPS.

\section{$4 \quad$ Setting and empirical strategy}

\subsection{Preliminaries}

This study brings new insights to understand how the internal labour migration decision takes place in a dynamic setting and how it affects the well-being of households left behind in the context of a developing country. I want to measure the effect of the migration decision on agricultural productivity. Since the labour migration reduces the labour force available to households, agricultural production can be negatively affected by migration mainly because in developing countries, the agricultural sector is highly labour-intensive. Therefore, the way that migration affects the agricultural productivity depends on whether or not the net gain from migration allows the household to invest enough in the agricultural sector to make up for the cost of forgone labour. To compute the agricultural productivity, I have only accounted for the main crops cultivated in all regions of Uganda to avoid selection bias related to geographical advantages of one crop to 
another. Therefore, I have added up the productions per hectare of maize, beans, coffee, peanuts, cassavas, bananas and potatoes.

Let us take equation 1 as a baseline model where $\alpha_{t}$ is the coefficient of interest that measures the average effect of labour migration on agricultural productivity in period $t(Y$ it $)$. LMit takes value one if household $i$ participates in labour migration in period $t$. Xit and $Z i$ are respectively timevariant and time-invariant characteristics of households.

$$
Y_{i t}=L M_{i t} \alpha+X_{i t} \gamma+Z_{i} \theta+\mu_{i}+\epsilon_{i t}
$$

The estimator of $\alpha_{t}$ using the Ordinary Least Squared (OLS) might be biased due to the endogeneity of the labour migration decision. Given the nature of the outcome per se, the main sources of endogeneity will be the existence of omitted variables and the simultaneity between migration decision and investment in the agricultural sector. In fact, when a household decides which member(s) to send outside, it simultaneously decides the level of agricultural production, given the (anticipated) net gain of migration, the land owned, and the available labour force (from remaining members and/or from labour they can hire in the village). In equation $1, \mu_{i}$ captures the time-invariant factors that might be correlated with LMit but is not observed by the econometrician. For instance, households involved in labour migration might have more members with higher abilities and a larger social network and may be more willing to take risks since there is no guarantee that the investment in migration will produce a positive gain.

To solve the simultaneity issue, we can add to equation 1 a second equation that estimates the labour migration decision. Yet, this does not solve the issue of omitted and unobserved factors. Another source of endogeneity might be the measurement error on outcomes of interest. Sometimes, it is difficult to measure, precisely, the households' agricultural productivity. Nevertheless, to reduce potential measurement error, the data on the agricultural production are collected in 6-month intervals, corresponding to the short and long cropping seasons. Even if measurement error is minimized in this way, we might still face a heteroscedasticity problem.

To correct for the potential endogeneity problem and the heteroscedasticity issue, I present in the next two sections an identification strategy that minimizes if not totally eliminates the bias.

\subsection{Identification strategy}

Due to the selection into the labour migration, the OLS provides biased estimates of the effect. The selection problems arise from many sources discussed in section 4.1. In the literature, different approaches have been developed to correct for the endogeneity problem due to the selection bias introduced by observed and unobserved variables. Different methods such as propensity score matching and its variants enable correcting for the bias based on observed variables in the static and dynamic analyses. ${ }^{\mathbf{1 1}}$ However, it is more difficult to be convinced that we have corrected for the selection due to the unobserved heterogeneity. Nevertheless, the Instrumental variables (IVs) approach attempts to correct for both types of selection by finding an exogenous shock that affects the variable source of endogeneity and that is not directly correlated with the outcome of interest. The problem is that finding such a variable is not an easy task. In the literature, some authors use the variations of rainfall as exogenous shock that motivates people in the rural area to move to find jobs elsewhere (Konseiga, 2007; Lucas, 1987). In our data, we did not find significant variation

11 See, e.g. Lechner (2009) for the evidence of the sequential matching approach. 
in rainfall for each district and it seems not to affect migration incentives. Besides, the variation in rainfall may be directly correlated with the agricultural productivity.

The IVs approach has been largely implemented in the literature to estimate the return to education using an exogenous variation in the supply side of education such as the reduction of the tuition fees, which is not correlated with the wages of individuals (see Card, 2001 for a review). In the economics of migration, empirical studies stress that the costs related to the migration are the main disincentive for households to involve in migration (Mendola, 2008; Mckenzie and Rapoport, 2007; Garip, 2008). Therefore, the instruments for labour migration are related to the household's social capital network, from which the household can have many resources (transportation to the destination place, a place to live and useful information about job opportunities). In this way, the monetary cost of migration and the uncertainty surrounding the potential returns from migration are significantly reduced. For this reason, the larger the household's social network is, the higher the propensity of migrating is. In this setting, authors distinguish the 'strong' social network from the 'weak' social network. The former is the network made up of household members and relatives who have experienced the labour migration and the latter is the network formed by people from the same village who have also experienced internal labour migration in the past. The weak social network is relevant in developing countries since it is common that people in the same village help one another. Therefore, the social network is a strong push factor to labour migration when the household faces a monetary constraint. We then expect to have a higher and stronger effect from the 'strong' social network.

Furthermore, other data sources may contain specific information about the people with whom the household members interact. Since in my data there are no specific questions about the household's social network, I follow the current literature by taking as a proxy for the household's 'strong' social network the number of household members who have experienced internal labour migration in the past and for the 'weak' social network, the labour migration rate at the district level. In this study, the household's 'strong' social network is captured by the number of household members who experienced labour migration in 2006, that is at least four years before the beginning of the period covered by the analysis. I take the much earlier prevalence of migration as an instrument to manage the potential correlation that might exist between the migration that occurred just before the period covered by the data and the agricultural productivity of the households. Nevertheless, the factors that led households to participate in migration five years ago may have led them to participate in migration today and then could be correlated with the current agricultural productivity.

In addition, it is not excluded that there are still unobserved time-invariant and/or time-varying variables that affect the migration propensity and production function over time, that is $E\left[L M_{i t} \times \mu_{i}\right] \neq 0$ and $E\left[L M_{i t} \times \epsilon_{-} i t\right] \neq 0$. To provide an illustration for the unobserved timevarying variables, based on the theory of learning by doing, it is expected that the more a household participates in migration, the higher the probability of succeeding in the destination place is. That could then increase the return to labour migration. Thereby, the migration prevalence in 2006 may not verify the restriction assumption as instrument. This raises the issue of the trade-off between the power of the instrument and the restriction assumption. Conley et al. (2012) offer a way to achieve efficiency in the case that the restriction assumption fails. The idea is to introduce the instruments in the outcome equation (the second stage of the two-stage least squared estimations) in order to test if their parameters are significantly different from zero and to have efficient confidence intervals for the causal effect. At this point, we do not know if the instruments for the household's social network (as presented in the literature) actually verify the exclusion restriction assumption because the authors usually just assume it is verified. I propose to test this assumption 
in this paper. Moreover, I will also test to see if the social network through ethnicity can be a push factor for the internal labour migration in Uganda.

To estimate the effect of migration over time on agricultural productivity, I specify the model as follows:

$$
\left\{\begin{array}{l}
M U_{t}^{*}=Z_{i} \beta+W_{i t} \alpha_{m}+\theta_{i} \gamma+\lambda_{i t}^{-1 / 2} \varepsilon_{i} \\
\operatorname{Prod}_{1 i t}=X_{i t} \alpha_{1}+\theta_{i} \gamma_{1}+\lambda_{i t}^{-1 / 2} \epsilon_{1 i} \\
\operatorname{Prod}_{0 i t}=X_{i t} \alpha_{0}+\theta_{i} \gamma_{0}+\lambda_{i t}^{-1 / 2} \epsilon_{0 i}
\end{array}\right.
$$

Where the system of equations that tests for the exclusion restriction assumption for the set of instruments is given by:

$$
\left\{\begin{array}{c}
M U_{t}^{*}=Z_{i} \beta+W_{i t} \alpha_{m}+\theta_{i} \gamma+\lambda_{i t}^{-1 / 2} \varepsilon_{i} \\
\operatorname{Prod}_{1 i t}=Z_{i} \beta^{1}+X_{i t} \alpha_{1}+\theta_{i} \gamma_{1}+\lambda_{i t}^{-1 / 2} \epsilon_{1 i} \\
\operatorname{Prod}_{0 i t}=Z_{i} \beta^{0}+X_{i t} \alpha_{0}+\theta_{i} \gamma_{0}+\lambda_{i t}^{-1 / 2} \epsilon_{0 i}
\end{array}\right.
$$

$\forall t \in\{1,2,3\}$ stands for the time period; the first period corresponds to the survey implemented in 2009. $M U_{i t}^{*}$ is the latent variable representing the migration utility function, which is related to the migration status, $L M_{i t}$, by the preference relation:

$$
L M_{i t}= \begin{cases}1 & \text { if } M U_{i t}^{*}>0 \\ 0, & \text { if } M U_{i t}^{*} \leq 0\end{cases}
$$

$\operatorname{Prod}_{1 i t}$ stands for the agricultural production per hectare of households involved in migration in period $t$ and $\operatorname{Prod}_{0 i t}$ the counterfactual agricultural productivity if households are not involved in labour migration in period $t$. In the model specification, the distribution of $\lambda_{i t}$ allows to account for the heteroskedasticity induced by the measurement error in agricultural productivity or by the fact that the way some variables are related with dependent variable can be different among individuals. In fact, the household social capital can affect households' migration decisions differently. $Z_{i}$ is the vector of instruments for the labour migration. In addition to the prevalence of migration at household level and at district level, I have added as instrument for the labour migration the household's relative income deprivation computed by using the monthly household total expenditures and the average total expenditure of the reference group for each household in the district. ${ }^{12}$ In the relative deprivation model of migration, Stack and Taylor (1991) argue that once we control for the absolute income gain from migration, relative income deprivation can be an incentive for households to participate in migration if both the HHs and its migrants feel less deprived. However, in the case where the migrants-sending HHs substitute its reference group with the group of households in the district of destination so that the income gain does not compensate the higher relative income deprivation given the new reference group, neither the household's absolute income, nor the relative income is going to be significant in the household's propensity to participate in temporary internal labour migration. Additionally, equation 3 allows to test for the exclusion restriction assumption of the instruments. In this case, if the set of

12 I have reported in appendix the details about the way that I compute the Index of relative deprivation for each household. 
parameters $\beta^{1}$ and $\beta^{0}$ are significantly different from zero, it means that the exclusion restriction assumption failed.

Table 3: Set of variables

\begin{tabular}{l|l}
\hline Inputs for agricultural production & $\begin{array}{l}\text { Hired labour (in terms of the number of days) } \\
\text { Adult equivalent } \\
\text { Total area planted } \\
\text { Percentage of households involved in agricultural sector within a } \\
\text { radius of } 5 \mathrm{~km}\end{array}$ \\
\hline Risk management & - Number of crops managed \\
\hline Head attributes & $\begin{array}{l}\text { Marital status } \\
\text { Education } \\
\text { Age }\end{array}$ \\
\hline Household characteristics & $\begin{array}{l}\text { Household wealth measured by the household total expenditures } \\
\text { Size } \\
\text { Share of members aged less than } 5 \text { years } \\
\text { Share of members aged more than } 65 \text { years } \\
\text { Share of members aged between } 6 \text { and } 14 \text { years } \\
\text { Share of female } \\
\text { Geographical deprivation }\end{array}$ \\
\hline Instruments for migration decision & $\begin{array}{l}\text { Number of members involved } \\
\text { in migration in } 2006 \\
\text { Migration rate at district level in } 2006 \\
\text { Wealth Deprivation }\end{array}$ \\
\hline
\end{tabular}

Source: Author's calculations based on UNPS.

$X_{i t}$ is the vector of covariates that I have categorized into four sub-groups as detailed in Table 3. These are households' head attributes, households' characteristics, inputs for agricultural production and risk management. In the absence of formal insurance on agricultural production, some households plant many crops to manage the risk related to negative shock, therefore, we expect to have a positive correlation between the number of crops and the agricultural productivity. Larson et al. (2015) report some irregularities in the information about the number of household members working on the farm. Therefore, I take as proxy for the household labour force the household adult equivalence scale. I also include some spatial variables such as the percentage of households involved in agricultural activities within a radius of $5 \mathrm{~km}$ and the relative geographical deprivation ${ }^{\mathbf{1 3}}$. The first variable can measure the extent to which households can learn new agricultural techniques from others near them. The set of variables $W$ it in the migration likelihood equation contains the same covariates as $X_{i t}$ except those related to the inputs of the agricultural production.

By assuming that $\epsilon_{i s} \sim \mathcal{N}\left(0, \sigma_{s i}\right)$, for $\mathrm{s}\{0,1\}$, and $\varepsilon_{i t} \sim \mathcal{N}(0, \varsigma)$, the matrix format of the system 2 can be written as follows:

${ }^{13}$ I compute the geographical deprivation using information on the geolocation of the household dwelling relative to the main road, main market, border post, administrative services, etc. in the district. 


$$
H_{i t}=\left(\begin{array}{c}
\operatorname{MU}_{i t}^{*} \\
\operatorname{Prod}_{1 i t} \\
\operatorname{Prod}_{0 i t}
\end{array}\right)_{\substack{\alpha_{m}, \alpha_{0}, \alpha_{1}, \gamma \\
\gamma_{0}, \gamma_{1}, \lambda_{i t}, \theta_{i}}} \sim \mathcal{N}\left(\begin{array}{l}
Z_{i} \beta+W_{i t} \alpha_{m}+\theta_{i} \gamma \\
Z_{i} \beta^{1}+X_{i t} \alpha_{1}+\theta_{i} \gamma_{1}, \\
Z_{i} \beta^{0}+X_{i t}^{-1} \alpha_{0}+\theta_{i} \gamma_{0}
\end{array}\left(\begin{array}{ccc}
\varsigma & 0 & 0 \\
0 & \sigma_{1}^{2} & 0 \\
0 & 0 & \sigma_{0}^{2}
\end{array}\right)\right)
$$

Since $M U_{i t}^{*}$ is unobservable I normalize $\varsigma$ to one. In addition, I assume that there are unobserved time-invariant variables $\theta_{i}$, that differently affect the migration decision and the agricultural production.

One implication of the model is that in each period, conditionally to the observed and unobserved variables, the vector of loading factors $\left(\gamma, \gamma_{1}, \gamma_{0}\right)$ and the variance of the distribution of $\left(\theta_{i}\right)_{i=1}^{N}$ drive the correlation between the migration decision and the production. In fact, given the set of parameters,

$\forall t$

$\operatorname{cov}\left(M U_{t}^{*}, \operatorname{Prod}_{1 i t}\right)=\gamma \times \gamma_{1} \times \operatorname{Var}\left(\theta_{i}\right)$ and $\operatorname{cov}\left(\operatorname{MU}_{t}^{*}, \operatorname{Prod} \operatorname{oit}\right)=\gamma \times \gamma_{0} \times \operatorname{Var}\left(\theta_{i}\right)$

In addition, across periods,

$\operatorname{cov}\left(M U_{i t}^{*}, M U_{i t+1}^{*}\right)=\varsigma \operatorname{cov}\left(\lambda_{i t}, \lambda_{i t+1}\right)$ and $\operatorname{cov}\left(\operatorname{Prod}_{i t}, \operatorname{Prod}_{i t+1}\right)=\sigma_{1} \times \operatorname{cov}\left(\lambda_{i t}, \lambda_{i t+1}\right)$

On the other hand, in order to identify all the parameters, one loading factor for each outcome has to be set to one; I choose $\gamma_{0}=1$. The likelihood function is defined as follows:

$L\left(\operatorname{prod}_{t}, L M_{t} \mid B, \sigma, \lambda, \theta\right)=\prod_{i=1}^{N} \prod_{t=1}^{3} f\left(\operatorname{Prod}_{1 i t}, L M_{i t}=1\right) \times f\left(\operatorname{Prod}_{\text {oit }}, L M_{i t}=0\right)$

$=\prod_{i \mid L M_{i t}=1} \prod_{t=1}^{3} f\left(\operatorname{Prod}_{1 i t} \mid Z_{i t} \beta^{1}+X_{i t} \alpha_{1}+\theta_{i} \gamma_{1}, \lambda_{i t}^{-1} \sigma_{1}\right) P\left(L M_{i t}=1 \mid Z_{i t} \beta+X_{i t} \alpha_{m}+\theta_{i} \gamma, \lambda_{i t}^{-1}\right)$

$\times \prod_{i \mid L M_{i t}=0} \prod_{t=1}^{3} f\left(\operatorname{Prod}_{0 i t} \mid Z_{i t} \beta^{0}+X_{i t} \alpha_{0}+\theta_{i} \gamma_{0}, \lambda_{i t}^{-1} \sigma_{0}\right) P\left(L M_{i t}=0 \mid Z_{i t} \beta+X_{i t} \alpha_{m}+\theta_{i} \gamma, \lambda_{i t}^{-1}\right)$

$=\prod_{i \mid L M} \prod_{i t=1}^{3} f\left(\operatorname{Prod}_{1 i t} \mid Z_{i t} \beta^{1}+X_{i t} \alpha_{1}+\theta_{i} \gamma_{1}, \lambda_{i t}^{-1} \sigma_{1}\right) \Phi\left(Z_{i t} \beta+X_{i t} \alpha_{m}+\theta_{i} \gamma, \lambda_{i t}^{-1}\right)$

$$
\times \prod_{\substack{\left.i \mid L M_{i t}=0 \\-\theta_{i} \gamma, \lambda_{i t}^{-1}\right)}} \prod_{t=1}^{3} f\left(\operatorname{Prod}_{0 i t} \mid Z_{i t} \beta^{0}+X_{i t} \alpha_{0}+\theta_{i} \gamma_{0}, \lambda_{i t}^{-1} \sigma_{0}\right) \Phi\left(-Z_{i t} \beta-X_{i t} \alpha_{m}\right.
$$

$\Phi($.$) is the standard normal cumulative function and f($.$) is a density function for a normal$ distribution. In the likelihood function $L(. \mid),. \lambda=\left(\left(\lambda_{1 i}\right)_{i=1}^{N},\left(\lambda_{2 i}\right)_{i=1}^{N},\left(\lambda_{3 i}\right)_{i=1}^{N},\right)$, and $B=$ $\left(\beta, \alpha_{m}, \alpha_{1}, \alpha_{0}, \gamma, \gamma_{1}, \gamma_{0}\right), \sigma=\left(\sigma_{1}, \sigma_{0}\right)$ are the set of parameters.

Considering the complexity of the likelihood function and because I want to estimate a mean effect of the internal labour migration for each household, I use the Bayesian approach that assumes that each parameter of the model has a distribution with non-zero mean and variance. In 
the setting of treatment analysis, this approach provides a simple way, from the computational point of view, to account for the selection due to unobserved variables. Also, it enriches the analysis by enabling the effect of internal labour migration to be heterogeneous between all households, which is important in terms of public policy implications. In fact, public policies should be more efficient if the specific population who suffer from the labour migration is better targeted.

Recently introduced in the treatment analysis, there are few empirical studies that have attempted to use this approach (See Heckman et al. (2012) and Chib and Hamilton (2002) for a review) and, particularly in the literature of internal labour migration, there is no study so far that I am aware of. In the next section, the procedure used to implement the distribution for each component of $B=\left(\beta, \alpha_{m}, \alpha_{1}, \alpha_{0}, \gamma, \gamma_{1}\right)$, the distribution of $\sigma, \theta_{i}$ and $\lambda_{i}=\left(\lambda_{1 i}, \lambda_{2 i}, \lambda_{3 i}\right)$ is described.

\subsection{Simulation procedure: posterior distribution}

First, I define a prior distribution for each parameter:

Parameters Prior distribution

$$
\begin{array}{ll}
\sigma=\left(\sigma_{1}, \sigma_{1}, \sigma_{0}\right) & \mathcal{N}_{3}\left(l_{0}, L_{0}\right) \\
B=\left(\beta, \alpha_{m}, \alpha_{0}, \gamma, \gamma_{1}\right) & \mathcal{N}_{k}\left(b_{0}, B_{0}\right)
\end{array}
$$

\section{$B$ is $k \times 1$ vector}

$$
\begin{array}{ll}
\theta_{i} & \mathcal{N}\left(\mu_{0}, v_{0}\right) \\
\lambda_{i t}, t=1,2,3 & \mathcal{G}\left(\frac{\varphi_{0 t}}{2}, \frac{\varrho_{o t}}{2}\right), \mathcal{G}(., .) \text { is a gamma density function }
\end{array}
$$

Therefore the posterior distribution is given by:

$$
\pi(B, \sigma, \theta, \lambda)=\pi\left(\sigma \mid l_{o}, L_{o}\right) \pi\left(B \mid b_{0}, B_{0}\right) \pi\left(\theta \mid v_{o}\right) \pi\left(\lambda \mid \frac{\varphi_{o t}}{2}, \frac{\varrho_{o t}}{2}\right) L\left(\operatorname{Prod}_{t}, L M_{t} \mid B, \sigma, \lambda, \theta\right) .
$$

To sample a distribution for each parameter, unobserved heterogeneity and time-varying scale, I follow the strategy proposed by Chib and Greenberg (1998), Chib and Hamilton (2002) and Lindley and Smith (1972) which can be resumed by the following steps ${ }^{\mathbf{1 4}}$

1. Initialize $B, \sigma, \theta_{i}, \lambda_{1 i}, \lambda_{2 i}, \lambda_{3 i}$

2. Sample $\sigma$ from a Metropolis Hastings algorithm. The posterior distribution is:

$$
h\left(\sigma \mid l_{o}, L_{o}, B, \theta,\left(\lambda_{1 i}\right)_{i=1}^{N},\left(\lambda_{2 i}\right)_{i=1}^{N},\left(\lambda_{3 i}\right)_{i=1}^{N}\right)=f\left(\sigma \mid l_{o}, L_{0}\right) \times L\left(\operatorname{Prod}_{t}, L M_{t} \mid B, \sigma, \theta, \lambda\right)
$$

To sample $\sigma$ from this distribution, the proposal density function in a multivariate-t student $q$ ( $\mu, V)$, where $\mu$ and $V$ are respectively the mode and the inverse of the negative of the Hessian matrix of the function $h($.$) evaluated at the mode.$

3. Sample the unobserved component of the vector $H_{i t}^{*}=\left(M U_{i t}^{*}, \operatorname{Prod}_{1 i t}^{*}, \operatorname{Prod}_{\text {oit }}^{*}\right), \forall t=$ $1,2,3$. 
$>$ If $L M_{i t}=1$ then sample first $M U_{i t}^{*} \mid B, \sigma, \theta_{i} \lambda_{1 i}, \lambda_{2 i}, \lambda_{3 i}$ from a normal distribution

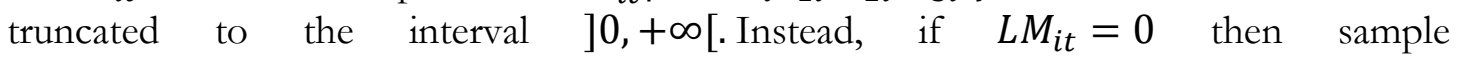
$M U_{i t}^{*} \mid B, \sigma, \theta_{i}, \lambda_{1 i}, \lambda_{2 i}, \lambda_{3 i}$ from a normal distribution truncated to the interval ] $\left.-\infty, 0\right]$.

$>\forall t \in\{1,2,3\}, i=1, \cdots, n$; sample either $\operatorname{Prod}_{1 i t}^{*}$ or $\operatorname{Prod}_{0 i t}^{*}$, independently from $i$ and $t$, from a normal distribution depending on whether $L M_{i t}$ is equal to 0 or 1 .

4. Sample the set of parameters $B \mid H_{i t}, b_{0}, B_{0}, \sigma,\left(\theta_{i}\right)_{i=1}^{N},\left(\lambda_{1 i}\right)_{i=1}^{N},\left(\lambda_{2 i}\right)_{i=1}^{N},\left(\lambda_{3 i}\right)_{i=1}^{N}$, from a normal distribution.

5. $\theta_{i} \mid z_{i t}, B, \sigma,\left(\lambda_{1 i}\right)_{i=1}^{N},\left(\lambda_{2 i}\right)_{i=1}^{N},\left(\lambda_{3 i}\right)_{i=1}^{N}$. Note that the posterior mean and the posterior variance of $\theta_{i}$ are different from one household to another.

6. Sample $\lambda_{i t} \mid H_{i t}, B, \sigma,\left(\theta_{i}\right)_{i=1}^{N}, \forall t=1,2,3$. The posterior parameters are also intrinsic to each household.

7. Repeat steps 2 to 6 to get a full distribution of the posterior distribution.

With the posterior distribution in hand, it is possible to compute various estimators of the effect of labour migration on household's production.

\subsection{Bayesian treatment effect of internal labour migration}

At this stage, I assume that we have the posterior distribution for all parameters, the time-invariant unobserved variables and the time scale variation. From the third step of the simulation algorithm, we have the posterior distribution of the outcome and its counterfactual for each household, that is $\left(\operatorname{Prod}_{i t}^{*}, \operatorname{Prod}_{\text {oit }}^{*}\right)$ for which two of them are observed and the other two are simulated depending on the household's migration status. In my specification, the independence assumption is similar to the one posited in the standard matching analysis and can be expressed as follows:

Assumption 1. $\operatorname{Prod}_{1 i t}^{*}, \operatorname{Prod}_{\text {oit }}^{*} \perp L M_{i t} \mid X_{i t}, Z_{i t}, W_{i t}, \theta_{i}, \lambda_{i t} ; \forall t=1,2,3$.

This assumption states that in each period, conditional on the data and on the posterior distributions of $\theta_{i}$ and $\lambda_{i t}$, the agricultural distribution is independent of the migration decision. Moreover, I assume here that there are no time-varying confounding factors that affect both the migration decision and the production decision. In fact, the time scale variation $\lambda_{i t}$ captures the deviation from the mean variance to correct for the measurement error and heterogeneous effect of some variables. Nevertheless, it goes beyond the assumption made in the potential outcome analysis because the independence assumption accounts for the presence of time-invariant confounders.

Under assumption 1, the effect of migration on household $i$ in period $t$ obtained from the posterior distribution is given by:

$$
\rho_{i t}=\left\{\begin{array}{l}
\operatorname{Prod}_{1 i t}-\operatorname{Prod}_{\text {oit }}^{*} \text { if } L M_{i t}=1 \\
\operatorname{Prod}_{1 i t}^{*}-\operatorname{Prod}_{\text {oit }} \text { if } L M_{i t}=0
\end{array}\right.
$$

Where $\operatorname{Prod}_{0 i t}^{*}$ and Prod Iit $^{*}$ are the simulated components of the agricultural productivity and $\operatorname{Prod}_{0 i t}$ and Prod $_{1 i t}$, the observed and actual agricultural productivity.

By assuming that I have achieved the convergence to the posterior distribution after $Q$ iterations from the simulation process, $\bar{\rho}_{i t}=\frac{1}{Q} \sum_{q=1}^{Q} \rho_{i t}^{q}$ is the mean effect for the household $i$ in period $t$. The denotation of the mean effect for $\bar{\rho}_{i t}$ is because we averaged on the posterior distribution. We 
can also aggregate the effect across time periods by $\bar{\rho}_{i}=\frac{1}{3 Q} \sum_{t=1}^{3} \sum_{q=1}^{Q} \rho_{i t}^{q}$ that is the mean effect of migration on the entire period covered by the analysis.

The Bayesian-average Mean Treatment Effect in period $t\left(B A M T E_{t}\right)$ and over the three periods $(B A M T E)$ can be expressed as follows:

$$
\operatorname{BAMTE}_{t}=\frac{1}{N} \sum_{i=1}^{N} \bar{\rho}_{i t} \quad \text { and } B A M T E=\frac{1}{N} \sum_{i=1}^{N} \bar{\rho}_{i}
$$

At the same time, we can compute the $B A M T E$ on the treated or on the non-treated $\left(B A M T E_{t}\right)$ in period $t$. They can be obtained from the expressions below, with $N_{1}$ and $N_{0}$ representing respectively the sample size of migrants-sending $\underline{\mathrm{HHs}}$ and non-migrants-sending $\underline{\mathrm{HH}}$.

$$
\begin{aligned}
& \text { BAMTET }_{t}=\frac{1}{N_{1}} \sum_{i \mid L M_{i t}=1}^{N} \bar{\rho}_{i t} \quad \text { BAMTET }=\frac{1}{3 N_{1}} \sum_{t=1}^{3} \sum_{i \mid L M_{i t}=1}^{N} \bar{\rho}_{i t} \\
& \text { BAMTENT }_{t}=\frac{1}{N_{0}} \sum_{i \mid L M_{i t}=0}^{N} \bar{\rho}_{i t} \quad \text { BAMTET }=\frac{1}{3 N_{0}} \sum_{t=1}^{3} \sum_{i \mid L M_{i t}=1}^{N} \bar{\rho}_{i t}
\end{aligned}
$$

I also follow Chib and Hamilton (2002) by grouping households depending on their probability of experiencing labour migration in the period $t$ conditional to covariate and unobserved heterogeneity, that is $P_{i t}=\Phi\left(Z_{i} \beta+X_{i t} \alpha_{m}+\theta_{i} \gamma,\left(\lambda_{i t}\right)^{-1}\right)$. At the $q^{\text {th }}$ iteration, $P_{i t}^{q}=$ $\Phi\left(Z_{i} \beta^{q}+X_{i t} \alpha_{m}^{q}+\theta_{i}^{q} \gamma^{q},\left(\lambda_{i t}^{q}\right)^{-1}\right)$. Therefore, by discretizing the distribution of probability at each period and at each iteration per decile, we can match households given that random probability inside each decile. Let $D_{h t}^{q}=\left\{i \mid P_{i t}^{q} \in\left(\frac{h-1}{10}, \frac{h}{10}\right)\right\}$ be the different groups for $h=$ $0,1, \cdots, 10$ and $t=1,2,3$. As pointed out by Chib and Hamilton (2002), the matching of individuals based on $P q$ is well defined even at the bottom tail of the distribution because households are self-matched since we are able to compute counterfactual for each household. In the frequentist analysis, the individuals with extreme values of propensity score are generally dropped from the estimation. The average effect in each decile group is given by:

$$
\delta_{h t}=\frac{1}{Q} \sum_{q=1}^{Q} \frac{1}{M_{h}^{q}} \sum_{i \in D_{h t}^{q}} \rho_{i t}^{q} \quad \text { and } \delta=\frac{1}{3 Q} \sum_{t=1}^{3} \sum_{q=1}^{Q} \frac{1}{M_{h}^{q}} \sum_{i \in D_{h}^{q}} \rho_{i t}^{q}
$$

where $M_{h}^{q}=\left|D_{h}^{q}\right|,|$.$| is the cardinality function.$

Moreover, we can also estimate the average effect for a group of households categorized by households' characteristics and head's characteristics. For example, one can be interested in the effect of migration on poorer households or female-headed households. To be more general, the average effect for a group $\Omega$ is:

$$
\delta=\frac{1}{Q \times \Omega} \sum_{i \in \Omega} \sum_{q=1}^{Q} \rho_{i t}^{q} \quad \text { and } \quad \delta_{\Omega}=\frac{1}{3 Q \times \Omega} \sum_{t}^{3} \sum_{i \in D_{t}} \sum_{q=1}^{Q} \rho_{i t}^{q} .
$$


In this section, I discuss the issues of convergence of the posterior distribution. I also comment the parameters that intervene in the likelihood function and the distribution of the effect of the internal labour migration on household agricultural production.

\subsection{Convergence check and strength of instruments}

\section{Convergence check}

I follow the algorithm reported in section 4.3 to reach the full set of posterior distribution for each parameter. To start with reliable parameters for each prior distribution and to thereby achieve the convergence more rapidly, I first run 4,000 iterations with 400 burn-ins from the simulation algorithm on a random training sample made up of a quarter of the initial sample ( 365 households) as suggested by Chib and Hamilton (2002). The algorithm is then run over 55,000 iterations with 5,000 burn-ins on the entire sample using the parameters obtained from the posterior distribution of the training sample. Figure 1 shows the distribution and the autocorrelation functions for each component of the variance-covariance matrix and the two loading factors.

Figure 1: Distribution and auto-correlation of the Variance posterior distribution

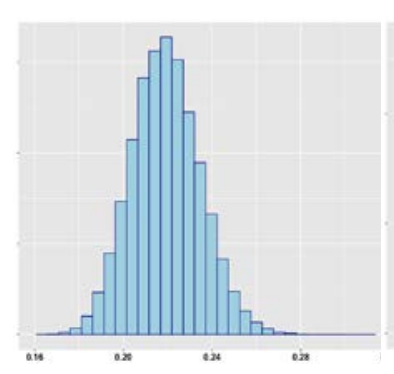

(a) $\sigma_{1}$

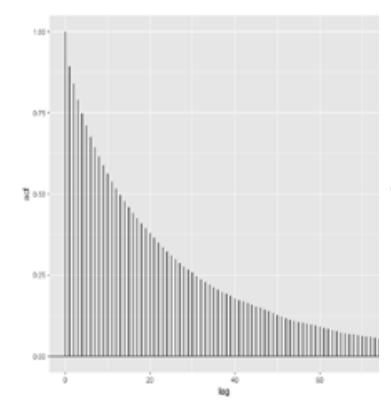

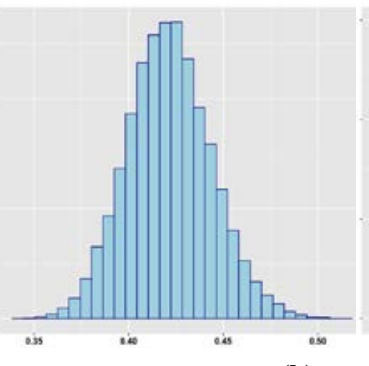

(b) $\sigma_{0}$

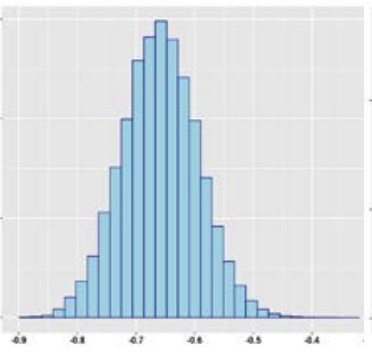

(c) $\gamma$

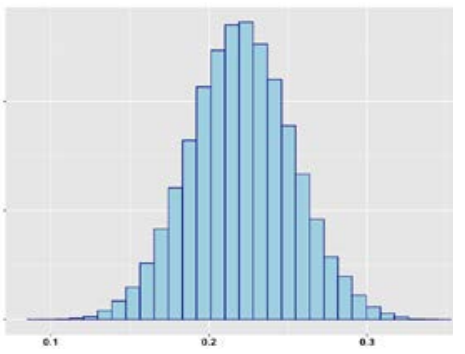

(d) $\gamma_{1}$
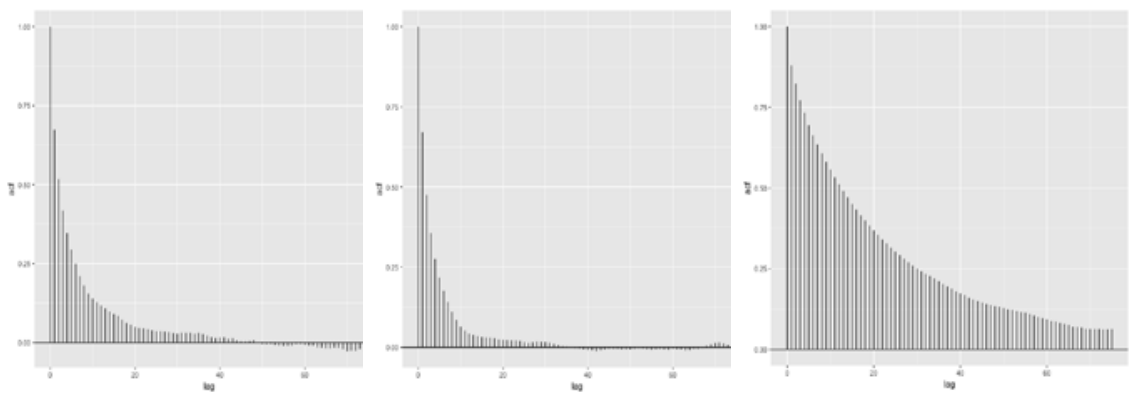

Source: Author's illustration based on UNPS.

As we can see, the autocorrelation functions reveal that our algorithm mixed well and the convergence is reached rapidly. Indeed, the autocorrelation over iterations drops very fast for all variances and a little less fast for the loading factors. Moreover, the posterior distribution of the loading factors in the migration decision equation is negative, meaning that households' timeinvariant unobservables tend to decrease the probability of participating in migration. On the other hand, the positive sign of the loading factor in the production function suggests that households' unobservables tend to increase the agricultural production. Therefore, there is a negative 
correlation between the participation in migration and the investment in agricultural production due to time-invariant unobservables.

To go further with the convergence check, I perform both the Geweke means convergence test and the stationary test proposed by Heidelberger and Welch (1983) on all parameters. The latter test states that a Markov chain Monte Carlo (MCMC) converges to the right posterior distribution if the mean of each parameter computed on a proportion of the sample on the top of the iteration is equal to the mean computing on the tail of the distribution. Geweke (1992) proposes using 10 per cent on the top and 50 per cent on the tail of the distributions. The convergence tests reveal that each component of the variance-covariance matrix reaches the convergence.

\section{Strength of instruments: testing the exclusion restriction}

I have reported in Tables 4 and 7 the mean and the standard deviation of the posterior distribution of all parameters of the equations 2 and 3 respectively. For both specifications, the posterior distribution of the two components of the variance-covariance matrix are all significant at the 5 per cent level, meaning that the 95 per cent credibility interval doesn't include zero. Moreover, the variances are higher in the first specification (equation 2) than in the specification that allows the instruments of migration to be correlated with the agricultural productivity. This might suggest that some instruments are correlated with the error term. Indeed, in Table 2 we can see that the migration rate experienced in 2006 at household and district levels tends to significantly decrease the household productivity. Alternatively, when I do not allow the instruments to intervene in the productivity equation, the migration rate at the district level is strongly positively correlated with the migration decision (see Table 3); however, when it is included in the productivity equation, it is no longer significant in the migration decision.

\subsection{Posterior distribution}

Here, I comment on the way that different variables affect the households' likelihood to invest in labour migration and also on how households' attributes impact the agricultural productivity. Upper and lower represent respectively the upper and lower bands of the interval of credibility for a p-value of 5 per cent. All results reported here are obtained from estimations on the balanced sample (sample $A$ ). To test if restraining our analysis to this sample could bias our results and in what way, I also run the model on the sample B. I find that the average effect of the labour migration on agricultural productivity is lower than the one obtained from sample $A$. This result is due to the fact that the average agricultural productivity in the sample $B$ is lower than the agricultural productivity of its counterpart in sample $A$. It seems that households who are absent from some survey rounds tend to have lower agricultural productivity ${ }^{15}$.

\section{Migration likelihood}

Unlike other studies that find a concave relationship between the probability to participate in migration and the level of households' wealth, I find that in the rural areas of Uganda this relationship is convex ${ }^{16}$. In fact, the propensity to invest in labour migration decreases with the household's wealth and the squared of the log of the wealth positively affects the migration decision. This means that below a certain level of wealth, households are less likely to participate in migration, perhaps because their expected gain does not offset other costs of migration that they cannot absorb. An increase of 1 per cent of wealth (measured in $\log$ ) decreases the probability

\footnotetext{
${ }^{15}$ Results are available on request.

${ }^{16} \mathrm{~A}$ two stage Heckman selection model leads to the same conclusion.
} 
to participate in labour migration by 3.2 per cent. Moreover, households headed by women are more likely to participate in migration; yet, the marital status of the head does not seem to differently affect the migration participation, only the households headed by singles have lower probability compared with households headed by a monogamously married head.

The composition of the household in terms of members and their educational attainment seem to be the strong determinants of the decision to participate in migration. Households with a higher proportion of children aged 5 or less have a significantly lower incentive to participate in labour migration. On the other hand, households with a higher proportion of adults aged more than 65 years have a higher incentive to get involved in migration. Furthermore, in the literature, some authors argue that once we control for the head's education, the average education among households' members might be a strong instrument for the labour migration. My results in this paper also confirm this finding as I find that the average education level in households significantly increases the participation in migration and has no effect on the agricultural productivity. Yet, the magnitude of the effect is too small, it only increases the probability by 0.006 . In the same vein, the household's relative deprivation in terms of total hours worked in domestic tasks by adult members seems to be a disincentive to get involved in migration and it has no significant effect on household's agricultural productivity at a 95 per cent credibility interval. Again, this variable appears to be a strong instrument favouring the labour migration. 
Table 4: Posterior distribution of parameters: sample A

\begin{tabular}{|c|c|c|c|c|c|c|c|c|c|}
\hline & \multicolumn{3}{|c|}{$\begin{array}{l}\text { Variables } \\
\text { Migration } \\
\text { likelihood }\end{array}$} & \multicolumn{3}{|c|}{$\begin{array}{l}\text { Agr. Productivity for } \\
\text { MIG-sending HHs }\end{array}$} & \multicolumn{3}{|c|}{$\begin{array}{l}\text { Agr. Productivity for } \\
\text { Non-MIG-sending HHs }\end{array}$} \\
\hline & mean & lower & upper & mean & lower & upper & mean & lower & upper \\
\hline Log wealth & -0.75 & -1.07 & -0.44 & 0.05 & -0.22 & 0.33 & 0.36 & 0.08 & 0.64 \\
\hline $\begin{array}{l}\text { Log wealth sq. } 10 \\
\text { If head is }\end{array}$ & 0.06 & 0.03 & 0.09 & 0.01 & -0.02 & 0.04 & -0.02 & -0.05 & 0.01 \\
\hline Married polygamous & 0.04 & -0.11 & 0.19 & -0.08 & -0.19 & 0.04 & 0.07 & -0.06 & 0.19 \\
\hline Divorced or & 0.06 & -0.18 & 0.30 & -0.13 & -0.30 & 0.04 & 0.01 & -0.20 & 0.21 \\
\hline Widow & -0.02 & -0.23 & 0.20 & -0.08 & -0.24 & 0.06 & -0.01 & -0.20 & 0.17 \\
\hline Single & -0.67 & -1.18 & -0.17 & -1.30 & -1.92 & -0.73 & 0.02 & -0.40 & 0.45 \\
\hline$=1$ if head $\mathrm{i}$ & 0.57 & 0.40 & 0.75 & 0.13 & 0.01 & 0.25 & -0.27 & -0.41 & -0.12 \\
\hline log Head age & 0.05 & -0.15 & 0.24 & 0.44 & 0.29 & 0.60 & 0.12 & -0.05 & 0.29 \\
\hline Head Educ & 0.03 & 0.01 & 0.05 & 0.02 & 0.01 & 0.03 & 0.00 & -0.02 & 0.02 \\
\hline Child & -1.15 & -1.52 & -0.78 & -0.04 & -0.35 & 0.27 & -0.40 & -0.70 & -0.10 \\
\hline $\begin{array}{l}\text { Individuals aged more than } \\
65\end{array}$ & 1.10 & 0.62 & 1.57 & -1.01 & -1.46 & -0.57 & -0.43 & -0.87 & 0.01 \\
\hline g HH size & 1.44 & 1.28 & 60 & 0.33 & 0.18 & 0.48 & 0.26 & 0.12 & 0.41 \\
\hline Avel & 0.04 & 0.01 & 0.08 & 0.00 & -0.02 & 0.03 & 0.00 & -0.02 & 0.03 \\
\hline Adu & -0.10 & -0.17 & -0.02 & 0.01 & -0.05 & 0.08 & -0.01 & -0.06 & 0.03 \\
\hline hil & 0.05 & -0.06 & 0.15 & -0.04 & -0.12 & 0.05 & 0.03 & -0.04 & 0.09 \\
\hline GEC & -0.07 & -0.13 & -0.02 & -0.06 & -0.10 & -0.03 & 0.00 & -0.03 & 0.03 \\
\hline Hea & 0.01 & -0.25 & 0.27 & -0.24 & -0.48 & -0.01 & -0.05 & -0.23 & 0.14 \\
\hline Ethr & -1.46 & -2.04 & -0.90 & 1.66 & 1.12 & 2.20 & 0.38 & -0.19 & 0.96 \\
\hline Ethnicity & -0.05 & -0.26 & 0.15 & -0.24 & -0.40 & -0.09 & 0.04 & -0.13 & 0.20 \\
\hline Center & 0.02 & -0.15 & 0.20 & -0.17 & -0.29 & -0.04 & -0.10 & -0.25 & 0.06 \\
\hline East & -0.59 & -0.76 & -0.43 & -0.22 & -0.35 & -0.10 & -0.25 & -0.39 & -0.10 \\
\hline North & -0.41 & -0.58 & -0.24 & -0.09 & -0.24 & 0.06 & -0.05 & -0.21 & 0.11 \\
\hline Hired lab & - & - & - & -0.02 & -0.06 & 0.01 & 0.03 & 0.00 & 0.06 \\
\hline Prox & - & - & - & -0.10 & -0.22 & 0.03 & -0.16 & -0.30 & -0.02 \\
\hline Area & - & - & - & -0.57 & -0.64 & -0.51 & -0.49 & -0.55 & -0.44 \\
\hline Num crops & - & - & - & 0.84 & 0.73 & 0.94 & 0.75 & 0.67 & 0.84 \\
\hline $\begin{array}{l}\text { labour Agriculture in } 1 \mathrm{~km} \\
\text { radius }\end{array}$ & - & - & - & 0.00 & -0.22 & 0.23 & 0.08 & -0.19 & 0.34 \\
\hline .. & 0.30 & 0.20 & & -0.08 & -0.14 & -0.01 & 0.01 & -0.10 & 0.11 \\
\hline Migratior & 0.22 & -0.39 & 0.83 & -0.74 & -1.34 & -0.14 & -2.15 & -2.80 & -1.51 \\
\hline Log Wealth DP & -0.00 & -0.02 & 0.02 & -0.01 & -0.03 & 0.01 & -0.00 & -0.03 & 0.03 \\
\hline & -1.45 & -2.03 & -0.88 & 4.60 & 4.06 & 5.14 & 4.93 & 4.35 & 5.51 \\
\hline Loading fact. & -0.66 & -0.79 & -0.53 & 0.22 & 0.16 & 0.29 & - & - & \\
\hline$\underline{\sigma}$ & - & - & - & 0.22 & 0.19 & 0.25 & 0.42 & 0.38 & 0.47 \\
\hline
\end{tabular}

Notes: Head-MIG equal 1 if the current place of residence of household is different from the place of household's head place of birth that is when the household's head has permanently migrated in the past (less than 11 years and more than two years). In the column of the likelihood migration, I have reported estimated parameters and they can't not be interpreted as a marginal effect. Only the sign is significant. However, in the text I will sometimes refer to the marginal effect computed for some variables.

Source: Author's calculations based on UNPS

The propensity to migrate also increases with the head's education and the size of the household, and decreases with the head's age; particularly, an increase in 1 per cent of household size increases the migration probability by 0.98 per cent. The geographical position of the household's dwelling place has a negative effect on migration participation as expected. I also test the hypothesis that the household's relative wealth deprivation can be a strong push factor for migration once controlling for the level of the wealth. It turns out that the relative wealth deprivation has no effect on the migration propensity. However, all other instruments appear to be intimately related with household migration decisions. In fact, having one more member who has experienced labour migration inside the household at least five years earlier increases the likelihood of migrating by 
0.045 of percentage points and, an increase of the migration rate at the district level by 1 per cent increases household migration by 0.033 of percentage points.

Moreover, the distribution of the unobservables shows that about 75 per cent of migrants-sending HHs have negative value for $\theta$ while it is the contrary for non-migrants-sending HHs. Figure A7 plots the inverse demand of migration as a function of unobservables. It emerges that the inverse demand of migration decreases with the time-invariant unobservables, meaning that the distribution of $\theta_{i}$ captures the unobserved distribution of the cost of migration that doesn't vary over time (see Figure A6), these are factors that discourage households year after year to not participate in labour migration and which tend to increase the agricultural productivity.

\section{Agricultural productivity}

As mentioned above, the total production aggregates the production of maize, beans, coffee, peanuts, bananas and potatoes per hectare. Furthermore, these crops constitute the most cultivated crops within the country and the agricultural productivity is expressed in kilogram per hectare. We can see from Table 2 that the investment process in the agricultural productivity differs according to the household migration status. Nevertheless, regardless of the migration status, the agricultural productivity does not change given the marital status and household's relative deprivation in terms of wealth, the domestic hours worked by adult household members and the geo-spatial position of the household dwelling place. On the other hand, both the migrants-sending HHs and nonmigrants-sending HHs production is positively affected by the household size and by the number of crops planted while their productivity is negatively affected by the total area plotted. The number of crops managed is usually used as a proxy of how households manage the risk associated with potential events such as the contamination of a particular crop by insects. The results suggest the importance of this factor for households involved in migration. In fact, cultivating one additional crop increases the agricultural productivity by 84 per cent for migrants-sending $\mathrm{HHs}$ and 76 per cent for non-migrants-sending HHs. Moreover, an increase of one hectare of planted area decreases the agricultural productivity by 53 per cent and 56 per cent respectively for migrantssending HHs and non-migrants-sending HHs.

The results suggest that the agricultural productivity of female-headed households is higher in the migrants-sending HHs group than in the non-migrants-sending HHs group. Since female-headed households are more likely to participate in migration, it seems that returns to migration allow them to invest more in the agricultural sector than households headed by males. Moreover, while belonging to the larger ethnic group at the district and country levels is respectively negatively and positively correlated with the migrants-sending HHs production, belonging to an ethnic group has no effect on non-migrants-sending HHs. Mwesigye and Matsumoto (2016) find in the case of Uganda that ethnic diversity tends to lower agricultural production; instead, my results suggest the contrary since the increase of the share of individuals belonging to the same ethnic group lowers the investment in agricultural productivity.

Regarding the labour hired to work on the farms, I find that the number of days that the households hired people to work on their farms does not affect migrants-sending HHs' productivity; yet, it increases the non-migrants-sending HHs' productivity. Moreover, while the agricultural productivity increases by 3 per cent with each additional year of education of the migrants-sending HHs head, the head's education has no effect within households not participating in migration. In parallel, the share of household members aged less than 5 years old tends to lower the agricultural productivity among the non-migrants-sending HHs group while it has no effect on the migrants-sending HHs' productivity. This means that non-migrants-sending HHs' agricultural productivity strongly depends on its household composition as compared to the migrants-sending HHs, which is in line with their decision to not participate in migration. 
The distribution of the individual's variance scale, $\left(\lambda_{i 1}, \lambda_{i 2}, \lambda_{i 3}\right)$ reveals that the conditional distributions of the agricultural productivity of the households belonging to the non-migrantssending households are more heteroscedastic than the counterpart for the migrants-sending households. Regarding the source of heteroscedasticity, this result means that the measurement error in agricultural productivity and the omission of some time-variant unobservables in the productivity equation are more likely to occur for the households that are not involved in labour migration.

\subsection{Distribution of the effect of labour migration on agricultural production}

In this section, I compare each household productivity to the counterfactual productivity obtained by simulation. Prior to this, I first evaluate to what extent my model accurately predicts the actual agricultural productivity distributions. Figure A5 shows that the predicted distributions are very close to the actual distributions, however, the variance is smaller than the one of the observed distribution. Besides, the average gap between the actual and the predicted value does not attain a production of two kilograms per hectare.

Table 5: Average effect of internal labour migration on agricultural productivity

\begin{tabular}{|c|c|c|c|c|c|c|c|c|c|c|c|}
\hline \multirow[b]{2}{*}{$\begin{array}{l}\text { Average } \\
\text { effect }\end{array}$} & \multirow[b]{2}{*}{ All } & \multicolumn{4}{|c|}{ MIG-sending $\mathrm{HHs}(B A M E T)$} & \multirow[b]{2}{*}{$\begin{array}{l}\text { Produc- } \\
\text { tion } \leq \text { med }\end{array}$} & \multirow[b]{2}{*}{ All } & \multicolumn{2}{|c|}{ Non MIG-sending } & \multicolumn{2}{|c|}{$\mathrm{HHS}(B A M E N T)$} \\
\hline & & All & $\begin{array}{l}\text { Female } \\
\text { headed }\end{array}$ & $\begin{array}{c}\text { Male } \\
\text { headed }\end{array}$ & $\begin{array}{l}\text { Produc- } \\
\text { tion }>\text { med }\end{array}$ & & & $\begin{array}{l}\text { Female } \\
\text { headed }\end{array}$ & $\begin{array}{c}\text { Male } \\
\text { headed }\end{array}$ & $\begin{array}{l}\text { Produc- } \\
\text { tion }>\text { med }\end{array}$ & $\begin{array}{l}\text { Produc- } \\
\text { tion } \leq \text { med }\end{array}$ \\
\hline & (1) & (2) & (3) & (4) & (5) & (6) & (7) & (8) & (9) & (10) & (11) \\
\hline Period 1 & $\begin{array}{l}0.26 \\
(0.03)\end{array}$ & $\begin{array}{c}0.27 \\
(0.07)\end{array}$ & $\begin{array}{c}0.39 \\
(0.14)\end{array}$ & $\begin{array}{c}0.21 \\
(0.08)\end{array}$ & $\begin{array}{c}0.89 \\
(0.07)\end{array}$ & $\begin{array}{l}-0.44 \\
(0.10)\end{array}$ & $\begin{array}{c}0.26 \\
(0.03)\end{array}$ & $\begin{array}{c}0.41 \\
(0.07)\end{array}$ & $\begin{array}{c}0.21 \\
(0.04)\end{array}$ & $\begin{array}{l}-0.50 \\
(0.03)\end{array}$ & $\begin{array}{l}1.00 \\
(0.04)\end{array}$ \\
\hline Period 2 & $\begin{array}{l}0.17 \\
(0.03)\end{array}$ & $\begin{array}{c}0.54 \\
(0.05)\end{array}$ & $\begin{array}{c}0.69 \\
(0.09)\end{array}$ & $\begin{array}{c}0.47 \\
(0.05)\end{array}$ & $\begin{array}{c}0.99 \\
(0.04)\end{array}$ & $\begin{array}{c}0.01 \\
(0.07)\end{array}$ & $\begin{array}{c}0.02 \\
(0.03)\end{array}$ & $\begin{array}{c}0.23 \\
(0.06)\end{array}$ & $\begin{array}{l}-0.05 \\
(0.04)\end{array}$ & $\begin{array}{c}-0.55 \\
(0.04)\end{array}$ & $\begin{array}{c}0.56 \\
(0.04)\end{array}$ \\
\hline Period 3 & $\begin{array}{l}0.16 \\
(0.02)\end{array}$ & $\begin{array}{c}0.30 \\
(0.04)\end{array}$ & $\begin{array}{c}0.37 \\
(0.08)\end{array}$ & $\begin{array}{c}0.26 \\
(0.05)\end{array}$ & $\begin{array}{c}0.78 \\
(0.04)\end{array}$ & $\begin{array}{l}-0.24 \\
(0.06)\end{array}$ & $\begin{array}{c}0.10 \\
(0.03)\end{array}$ & $\begin{array}{c}0.25 \\
(0.06)\end{array}$ & $\begin{array}{c}0.05 \\
(0.03)\end{array}$ & $\begin{array}{l}-0.51 \\
(0.03)\end{array}$ & $\begin{array}{c}0.68 \\
(0.03)\end{array}$ \\
\hline Total & $\begin{array}{l}0.20 \\
(0.03)\end{array}$ & $\begin{array}{c}0.37 \\
(0.05)\end{array}$ & $\begin{array}{c}0.48 \\
(0.10)\end{array}$ & $\begin{array}{c}0.31 \\
(0.06)\end{array}$ & $\begin{array}{c}0.89 \\
(0.05)\end{array}$ & $\begin{array}{l}-0.22 \\
(0.08)\end{array}$ & $\begin{array}{c}0.13 \\
(0.03)\end{array}$ & $\begin{array}{c}0.30 \\
(0.06)\end{array}$ & $\begin{array}{c}0.07 \\
(0.04)\end{array}$ & $\begin{array}{l}-0.52 \\
(0.03)\end{array}$ & $\begin{array}{c}0.75 \\
(0.04)\end{array}$ \\
\hline
\end{tabular}

Note: 'med' stands for the median of the corresponding distribution.

Source: Author's calculations based on UNPS.

Although the Bayesian average mean effect $(B A M E)$, the Bayesian average effect on the treated (BAMET), and the Bayesian average effect on the non-treated (BAMENT) of the internal labour migration are all positives ${ }^{17}$ over the entire sample (see columns (1), (2) and (3) of Table 5), the distribution of the effect represented in Figure 2 and the average effect on the specific subgroup tell us a different story. Indeed, there are households for whom the effect is negative while for other households the effect is positive. This result then suggests that the internal labour migration affects the households' agricultural productivity differently, thus, aggregating the effect over the entire population could hide other facets of the actual impact of the labour migration.

For all periods, the $B A M E T$ is higher than the average mean effect on the non-treated ( $B A M E N T)$. Furthermore, while the $B A M E T$ increases between the first and the second periods and decreases between the second and the third periods, the BAMENT decreases over time. The households headed by women always have a higher return to migration than households headed by men. Therefore, internal labour migration might be a way for female-headed households to increase their agricultural productivity, which is an interesting result since the literature on poverty usually depicts worse livelihood conditions for this group of households. Nevertheless, since

\footnotetext{
${ }^{17}$ The average effect does not exceed the gain of two kilograms per hectare.
} 
female headship is highly correlated with being a migrant household, one might think that this is mostly due to the fact that the husband has migrated. Thus, it is more likely that transfers of the husband to the household left behind are higher. However, only about 3 per cent of female-headed households participating in migration have a husband who has migrated and those have in fact the highest effect on migration.

Figure 2: Distribution of the effect of internal migration on agricultural production

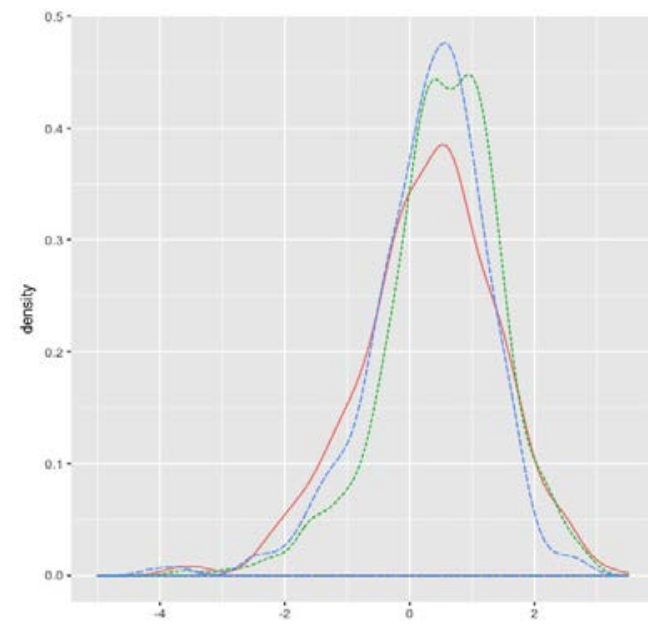

Percentage of HHs with BAMET>0: $63.0 \%, 76.8 \%$, and $67.7 \%$

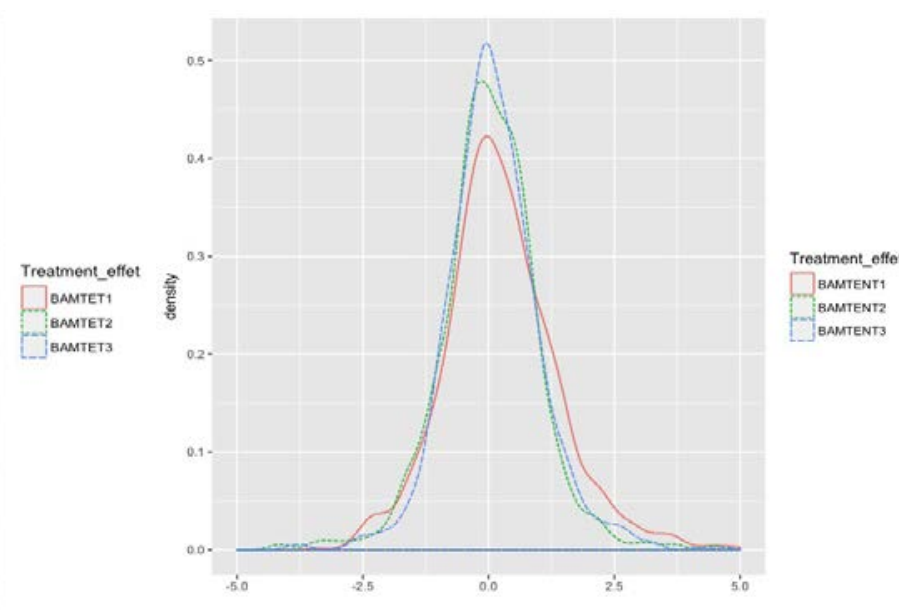

Percentage of HHs with BAMTENT>0: $56.6 \%, 51.3 \%$ and $52.7 \%$

Source: Author's illustration based on UNPS.

Among migrants-sending HHs, there are respectively 63 per cent, 76.8 per cent and 67.7 per cent of the households for which the effect is positive from the first to the third period. Results in columns (5) and (6) reveal that, among households who decide to participate in migration, the larger farmers are those who benefit the most from the internal labour migration compared to the smaller farmers. This implies that the larger farmers are more likely to invest the return to migration in the agricultural sector. Among households belonging to the non-migrants group, we obtain a similar result that larger farmers would have had positive return by investing in labour migration. Instead, for the smaller farmers, the results suggest that the internal labour migration tends to decrease the agricultural productivity. Everything happens as if smaller farmers bear all of the labour cost induced by the migration and that the major part of the positive return to migration, if there is any, is devoted to non-agricultural productivity.

Regarding the distribution of the effect by region, we have a higher share of migrants-sending HHs who benefit from the labour migration (about 75 per cent) in the western part of Uganda and it is in this region that the agricultural production is also the highest. This result and the fact that the larger farmers are positively affected by the labour migration lead to think that there is no reason to believe that the labour migration will be a great threat to food security and the stability of the food prices in Uganda. Another thing we could look at is if risk diversification (by planting many crops) allows households to increase the benefit of migration. Our results lead to mitigated effects since the households who have planted many crops have higher returns from migration for a period and sometimes they have the smallest return in another period.

To go further, one might be interested in knowing how the effect changes when the likelihood of participating in migration increases. Figure A8 shows that the effect of migration on agricultural productivity increases with the likelihood of participating in migration. Moreover, the dispersion 
of the effect within each decile increases when the households are more likely to participate in migration. Furthermore, the average effect of migration is higher for those with negative timeinvariant unobservables compared to those with positive unobservables. Therefore, the selection into the participation in migration due to unobservables is also correlated with the average effect and the correlation is positive.

\section{Conclusion and discussion}

To my knowledge, few studies have investigated the effect of internal labour migration on agricultural productivity. This might be due to the difficulty of successfully identifying the causal impact of migration since households select themselves into labour migration. Therefore, the migration participation is endogenous to the agricultural productivity. This paper fills a gap in the literature by investigating the distribution of the effects of the temporary internal labour migration on households living in the rural areas of Uganda. The outcome of interest is the agricultural productivity in kilograms per hectare of six crops (maize, beans, coffee, peanuts, bananas and potatoes) planted in all regions of Uganda. I find that the average effect of the internal labour migration on the agricultural productivity is positive; the average effect on the households participating in migration is around 0.37 in terms of difference of the logarithm of agricultural productivity, corresponding to a 44 per cent increase in agricultural productivity. This is in line with the NELM theory which argues that migration enables households to invest in the agricultural sector.

However, as I allow the effect to be heterogeneous between households, it emerges that even if the average effect is positive, there are some households for which labour migration decreases their agricultural productivity. These households are mostly small farmers and are therefore more likely to be poor. Moreover, about half of the households that do not participate in labour migration across rounds would have had higher levels of agricultural productivity if they had participated in labour migration. This study thus brings new insights into how internal labour migration affects households' agricultural productivity. This kind of analysis is possible through the introduction of the Bayesian approach in the treatment analysis by allowing to self-match each household.

Moreover, the Bayesian framework enables to test the exclusion restriction assumption for the instruments and to account for its violation. Indeed, in the migration literature, some papers use previous participation in migration at the household and community levels as instruments for the current migration participation. The problem is that there is no evidence that these variables are exogenous, meaning that they are not correlated with the households' livelihoods. In this paper I test this hypothesis when the outcome of interest is the agricultural productivity and it emerges that the migration decision taken five years earlier is highly correlated with the current agricultural productivity. Moreover, when I introduce the instruments in the agricultural productivity, the effect of the time-invariant unobserved factors on the likelihood of participating in migration increases significantly while its effect on the agricultural productivity does not change. This may suggest that factors that encouraged households to participate in migration in the past still have an impact on their agricultural production decision today.

I also estimate the average effect within each percentile of the probability of participating in labour migration. It turns out that the effect of migration on agricultural productivity increases with the likelihood of participating in migration, which is good news in terms of achieving optimality. 
Although I attempt to limit the bias on my estimation results, they might suffer from many weaknesses. First, I don't allow the parameters in each equation to vary across the survey rounds, which could bias the posterior distribution of the counterfactual outcomes since the changes across periods are only due to the households' attributes and not to the way that these attributes affect the agricultural productivity.

\section{References}

Abbring, J. 2003. Dynamic Econometrics Program Evaluation. IZA Discussion paper, 804.

Adaku, A. 2013. The effect of rural migration on agricultural production in the Northern region of Ghana. Journal of Agricultural Science and Applications, 2(4), 193-201.

Asankha, P., and Takashi, Y. 2011. Impacts of Universal Secondary Education Policy on Secondary School Enrollments in Uganda. Journal of Accounting, Finance and Economics, 1, 16-30. 3

Bandiera, O., and Rasul, I. 2002. Social Network and Technology Adoption in Northern Mozambique. DEDPS-London school of Economics and Political Science, 35.

Baudasse', T., and Re'mi, B. 2014. Gender Inequality and Emigration: Push factor or selection process. International Economics, 139, 19-47.

Bryan, G., Chowdhury, S., and Mobarak, A.M. 2014. Underinvestment in a Profitable Technology: the Case of Seasonal Migration in Bangladesh. Econometrica, 82(5), 1671-1748.

Bukuluki, et al. 2015. Migration in Uganda: A rapid country profile 2013. International Organization for Migration (IOM). 3

Card, D. 2001. Estimating the Return to Schooling: Progress on Some Persistent Econometric Problems. Econometrica, 69(5), 1127-1160. 9.

Carneiro, P., Hansen, K.T, and Heckman, J.J. 2003. Estimating Distributions of Treatment Effects with an Application to return to schooling and measurement of the effects of uncertainty on college choice. International Econometric Reviews, 44, 361-422. 1

Chib, S., and Greenberg, E. 1998. Analysis of multivariate probit models. Biometrika, 85(2), 347361. 13, 24

Chib, S., and Hamilton, B.H. 2002. Semiparametric Bayes analysis of longitudinal data treatment models. Econometric Reviews. 13, 14

Conley, T. G., Hansen, C. B., and Rossi, P. E. 2012. Plausibly Exogenous. The Review of Economics and Statistics, 94(1), 260-272. 10

Davis, B., Carletto, G., and Winters, P. 2010. Migration, Transfers and Economic Decision Making among Agricultural Households: an Introduction. The Journal of Development Studies, 46, 1-13. 2

De Brauw, A. 2010. Seasonal Migration and Agricultural Production in Vietnam. The Journal of Development Studies,46, 114-139. 1, 2

De Haan, A. 1999. Livelihoods and poverty The role of migration a critical review of the migration literature. The Journal of Development Studies, 36(2), 1-47. 1, 2

Deininger, K. 2003. Does cost of schooling affect enrollment by the poor? Universal primary education in Uganda. Economics of Education Review, 22, 291-305. 
Dinkelman, T., and Mariotti, M. 2016. The long Run Effects of Labour Migration on Human Capital Formation in Communities of Origin. Cambridge, MA: National Bureau of Economic Research (NBER).

Garip, F. 2008. Social Capital and migration: how do similar Resources Lead to Divergent Outcomes. Demography, 45(3), 591-617. 2, 9

Garlick, J., Leibbrandj, M., and Levinsohm, J. 2016. Individual Migration and Household Incomes. National Bureau of Economic Research. 2

Geweke, J. 1992. Evaluating the Accuracy of Sampling-Based Approaches to Calculating Posterior Moments. In Bayesian Statistics 4 (ed JM Bernardo, JO Berger, AP Dawid, and AFM Smith). Oxford: Clarendon Press. 16

Glick, P., and Sahn, D. 2006. The Demand for Primary Schooling in Madagascar: Price, Quality, and the choice between Public and Private Providers. Journal of Development Economics, 79(2), $118-145$.

Gonzales, R., Aranda, P., and Mendiza'bal, J. 2016. Is Microfinance Truly Useless for Poverty Reduction and Women Empowerment? A Bayesian Spatial-Propensity Score Matching Evaluation in Bolivia. Partnership for Economic Policy (PEP), 10.

Heckman, J.J., Ichimura, H., Smith, J., and Todd, P. 1998. Characterizing Selection Bias Using Experimental Data. Econometrica, 66(05), 1017-1098.

Heckman, J.J., Lopes, H.F., and Piatek, R. 2012. Treatment Effects: A Bayesian Perspective. Econometric Reviews. 13

Heidelberger, P., and Welch, PD. 1983. Simulation run length control in the presence of an initial transient. Opns Res.,31, 1109-1144. 16

Huylebroeck, L., and Kristof, T. 2015. Universal Secondary Education (USE) in Uganda: blessing or curse? The impact of USE on educational attainment and performance. In: Reyntjens, F., $V$ andeginste, S. and M. Verpoorten (eds) L'Afrique des Grands Lacs: Annuaire 2014-2015. Antwerp: University Press Antwerp, 349-372.

Imbens, G., and Angrist, J. 1994. Identification and Estimation of Local Average Treatment effects. Econometrica, 62(2), 467-475.

Jagger, P., Shively, G., and Arinaitwe, A. 2012. Circular migration, small-scale logging, and household livelihoods in Uganda. Popul Environ, 34, 235-256. 3

Konseiga, A. 2007. Household Migration Decisions as Survival Strategy: The Case of Burkina Faso. Journal of African Economies, 16, 198-233. 9

Kuhn, R. 2015. Internal Migration: Developing Countries. International Encyclopedia of the Social and Behavioral Sciences, 12(2nd edition), 433-442. 2

Larson, D., Savastano, S., Murray, S., and Palacios-Lo'pez, A. 2015. Are Women Less Productive Farmers? How Markets and Risk Affect Fertilizer Use, Productivity, and Measured Gender Effects in Uganda. Policy Research Working Paper. Washington, DC: World Bank Group, 7241. 11

Lechner, M. 2009. Sequential Causal models for the Evaluation of labour market Programs. Journal of Business and Economic Statistics, 27(01). 9

Lechner, Michael, and Miquel, Ruth. 2001. Potential Outcomes Approach to Dynamic Program Evaluation-Part I: Identification. IZA Discussion Papers. Bonn: Institute for the Study of Labor. 
Lindley, D.V., and Smith, A.F. 1972. Bayes Estimates for the Linear Model. Journal of the Royal Statistics Society. Series B (Methodological), 34(1), 1-41. 13

Lucas, R. 1987. Emigration to South Africa's Mines. America Economic Review, 77(3), 313-330. 9

Mckenzie, D., and Rapoport, H. 2007. Network Effects and the Dynamics of Migration and Inequality: Theory and evidence from Mexico. Journal of Development Economics, 84, 1-24. 9

Mckenzie, D., Gibson, J., and Stillman, S. 2010. How Important is Selection: Experimental vs Non-experimental Measures of the Income Gains from Migration. Journal of the European Economic Association, 8(4), 913-945.

Mendola, M. 2008. Migration and Technological Change in Rural Household: Complements or Substitutes? Journal of Development Economics, 85, 150-175. 1, 2, 9

Mu, R., and Van de Walle, D. 2011. Left behind to farm? Women's labour re-allocation in rural china. Labour Economics, 18, 83-97. 1, 2

Muto, M. 2009. The impacts of mobile phone coverage expansion and personal networks on migration: evidence from Uganda. Prepared for presentation at the international association of Agricultural Economists conference, Beijing, China, August 16-22. 2, 3

Mwesigye, F, and Matsumoto, T. 2016. The Effect of Population Pressure and Internal Migration on Lands Conflicts: Implications for Agricultural Productivity in Uganda. World Development, 79(01), 25-39. 1, 2, 19

Ndiaye, A. S., Niang, O. K., Ndione, Y. C., and Dedehouanou, S.E. 2016. Migration, Remittances, Labour Market and Human capital in Senegal. Partnership for Economic Policy (PEP), 10.

Orazem, P, and E., King. 2008. Schooling in Developing Countries: The Roles of Supply, Demand and Government Policy. In Hollis Chenery and T.N. Srinivasan (eds), Handbook of Development Ecconomics. Amsterdam: Elsevier.

Penny, A., Ward, M., Read, T., and Bines, H. 2008. Education sector reform: The Ugandan experience. International Journal of Educational Development, 28, 268-285.

Rutaremwa, G. 2011. Internal and International Labour Migration in Uganda: The contribution of Remittances to Household Livelihoods. Makerere University, presented in African conference on Population. 3

Shannon, C.E. 1948. A Mathematical Theory of Communication. The Bell System Technical Journal, 27, 379-423,623-656.

Sianesi, B. 2004. An Evaluation of the Swedish System of active labour Market Programs in the 1990s. The Review of Economics and Statistics, 86(1), 133-155.

Ssewamala, F., Wang, J., Karimli, L., and Nabunya, P. 2011. Strengthening Universal Primary Education in Uganda: The potential role of an asset-based development policy. International Journal of Education Development, 31, 472-477. 3

Stack, O, and Taylor, J. E. 1991. Migration Incentives, Migration types: Role of relative deprivation. The Economic Journal, 101, 1163-1178. 2, 11

Stark, O., and Bloom, D. 1985. The New Economics of Labour Migration. American Economics Review, 75(2), 173-178. 1

Stark, O., and Taylor, J. E. 1989. Relative Deprivation and International Migration. Demography, 26(1), 1-14.

UBOS, Uganda Bureau of Statistics. 2013. Uganda Panel National Survey-W ave III report. Tech. rept. 5 
Vasilaky, K., and Leonard, K. 2016. As Good as the Network they Keep?: Improving the Outcomes Through the Weak Ties in Rural Uganda. Forthcoming. Economic Development and Cultural Change. 


\section{Appendices}

Appendix A: Distribution of education, ethnicity and agricultural production in Uganda

Figure A1: Agricultural productivity of grain by head's years of education and by average years of education in household
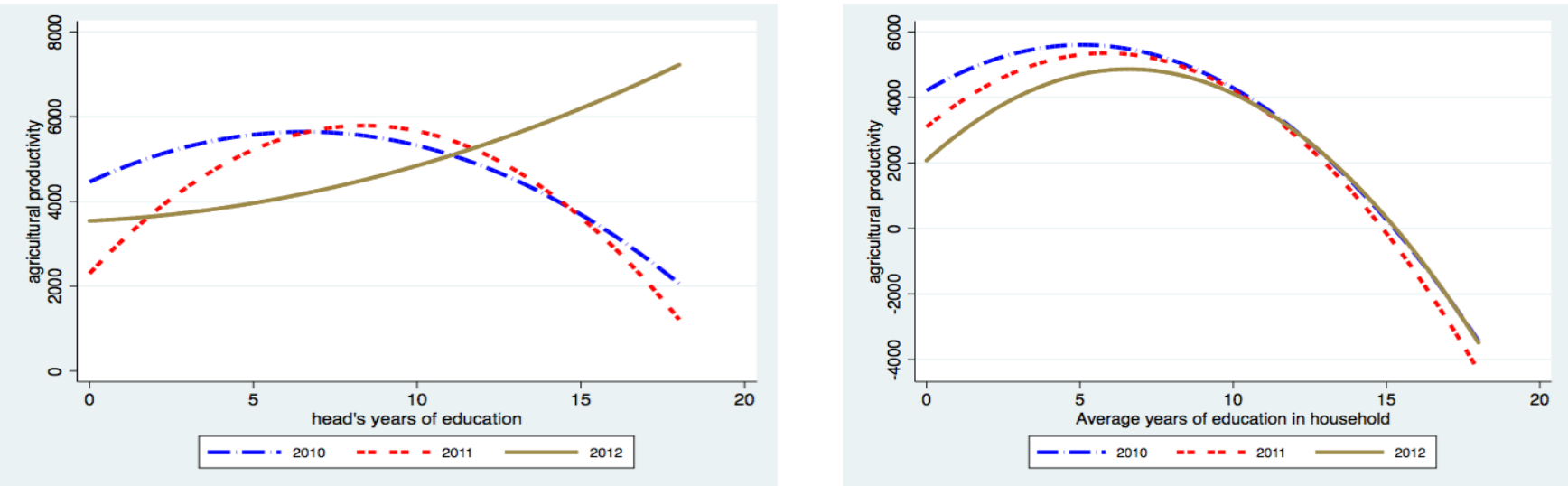

Source: Author's illustration based on UNPS.

Figure A2: Education distribution in Uganda

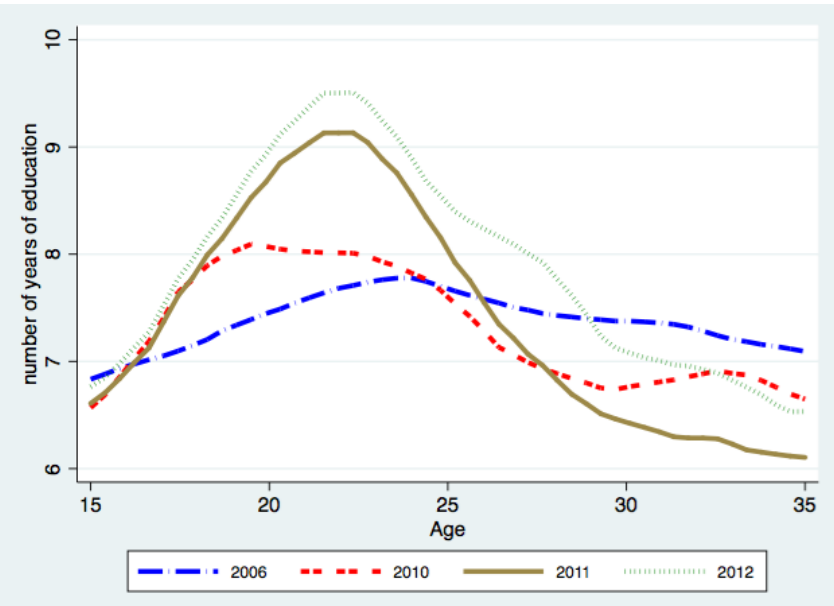

productivity

Source: Author's illustration based on UNPS.
Figure A3 Ethnicity and agricultural

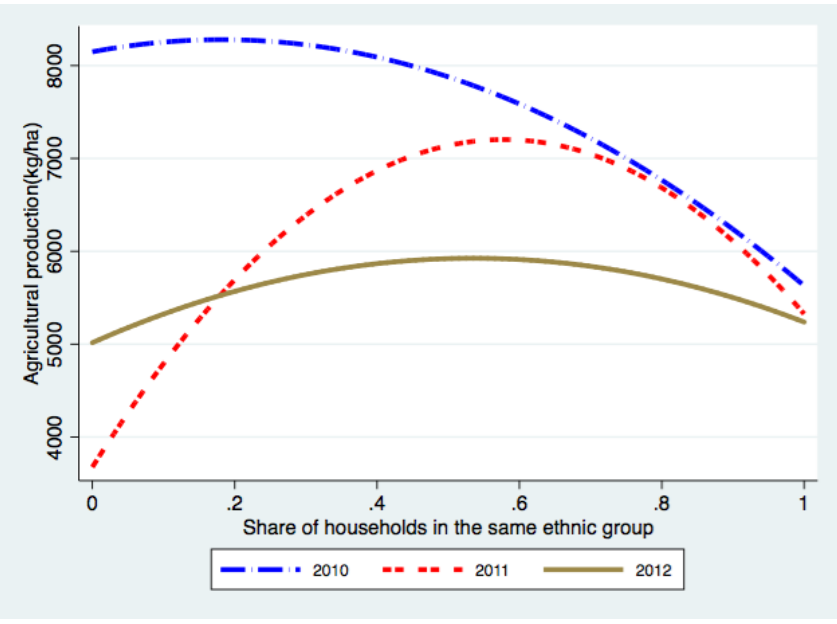

Source: Author's illustration based on UNPS 
Figure A4: Duration of migration and share of household members involved in migration

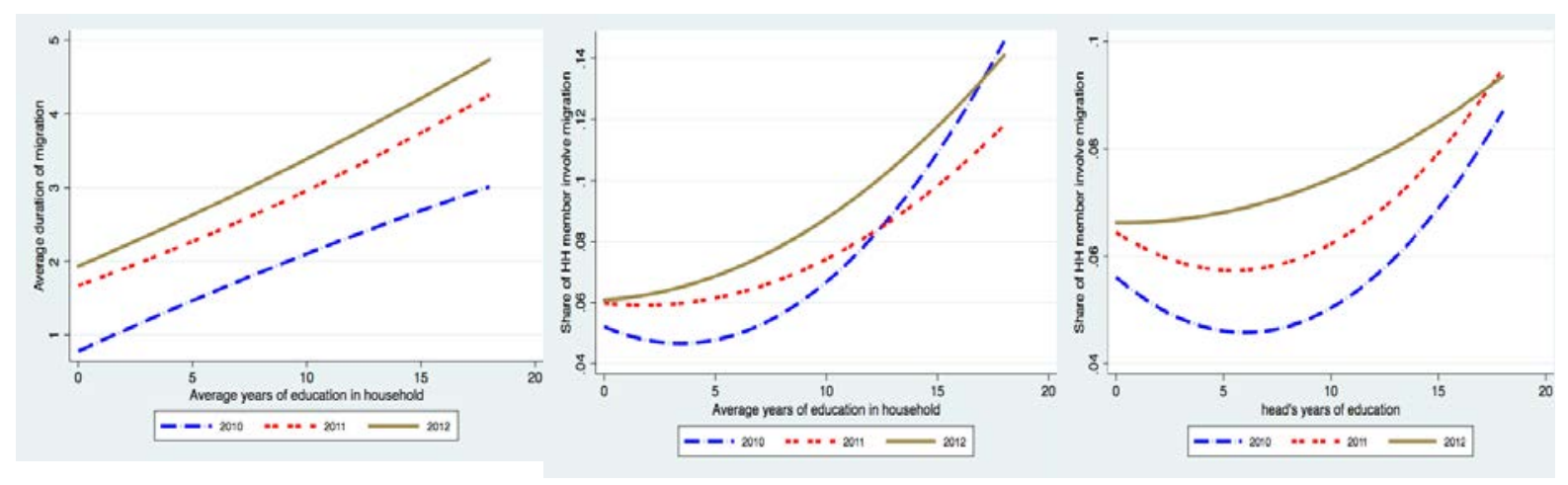

Source: Author's illustration based on UNPS.

Table A1: Household migration status and previous permanent migration status of household head

\begin{tabular}{lllllll}
\hline & \multicolumn{3}{c}{ Migrants-sending HHs } & \multicolumn{3}{l}{ Non Migrants-sending } \\
& \multicolumn{3}{c}{ HHs } \\
\hline Head-migrants & 2010 & 2011 & 2012 & 2010 & 2011 & 2012 \\
Head non-migrants & 13.1 & 12.4 & 13.4 & 86.9 & 87.6 & 86.6 \\
\hline
\end{tabular}

Source: Author's calculations based on UNPS. 
Table A2: Posterior distribution of parameters assuming that instruments verify the restriction assumption

\begin{tabular}{|c|c|c|c|c|c|c|}
\hline \multirow[t]{2}{*}{ Variables } & \multicolumn{2}{|r|}{$\begin{array}{l}\text { Migration } \\
\text { likelihood }\end{array}$} & \multicolumn{2}{|c|}{$\begin{array}{l}\text { Agr. Productivity for } \\
\text { MIG-sending } \mathrm{HHS}\end{array}$} & \multicolumn{2}{|c|}{$\begin{array}{l}\text { Agr. Productivity for } \\
\text { Non MIG-sending } \mathrm{HHS}\end{array}$} \\
\hline & Mean & SD & Mean & $\overline{\mathrm{SD}}$ & Mean & $\overline{S D}$ \\
\hline Log wealth & -1.04 & 0.17 & 0.56 & 0.14 & 0.12 & 0.14 \\
\hline Log wealth sq & 0.09 & 0.02 & -0.03 & 0.01 & 0 & 0.01 \\
\hline Married poly & -0.01 & 0.07 & -0.06 & 0.06 & 0.08 & 0.07 \\
\hline Div. sep & 0 & 0.12 & -0.09 & 0.09 & 0.14 & 0.11 \\
\hline Widow & -0.01 & 0.11 & -0.18 & 0.08 & 0.03 & 0.10 \\
\hline Single & -0.64 & 0.25 & 0.04 & 0.23 & -0.08 & 0.21 \\
\hline Head gender & 0.5 & 0.09 & 0.09 & 0.06 & -0.26 & 0.08 \\
\hline Log Head age & 0.05 & 0.1 & 0.64 & 0.08 & 0.07 & 0.08 \\
\hline Head Educ. & 0.03 & 0.01 & 0.02 & 0.01 & 0 & 0.01 \\
\hline Head-MIG & 0.06 & 0.13 & -0.11 & 0.12 & -0.01 & 0.10 \\
\hline Children less than 5 & -1.11 & 0.19 & 0.15 & 0.16 & -0.43 & 0.15 \\
\hline Individuals aged more than 65 & 0.96 & 0.24 & -1.02 & 0.22 & -0.58 & 0.22 \\
\hline Log $\mathrm{HH}$ size & 1.36 & 0.08 & 0.35 & 0.08 & 0.19 & 0.07 \\
\hline AVE educ. in hh & 0.04 & 0.02 & -0.01 & 0.01 & 0.01 & 0.01 \\
\hline Adult domes. lab DP. & -0.06 & 0.04 & -0.01 & 0.03 & 0 & 0.02 \\
\hline Children domes. lab. DP. & 0.05 & 0.05 & -0.03 & 0.04 & 0.02 & 0.03 \\
\hline Geo-spatial DP. & -0.02 & 0.03 & -0.05 & 0.02 & 0 & 0.02 \\
\hline Hired lab & 0 & 0 & -0.02 & 0.02 & 0.01 & 0.02 \\
\hline Proxy of $\mathrm{HH}$ labour & - & - & -0.14 & 0.07 & -0.07 & 0.07 \\
\hline Area planted & - & - & -0.61 & 0.04 & -0.51 & 0.03 \\
\hline Nb. crops & - & - & 0.85 & 0.05 & 0.75 & 0.04 \\
\hline Agriculture in $1 \mathrm{~km}$ radius & - & - & -0.27 & 0.11 & -0.02 & 0.14 \\
\hline $\begin{array}{l}\text { Ethnicity concentration (at } \\
\text { country level) }\end{array}$ & -1.47 & 0.29 & 2.61 & 0.27 & 0.06 & 0.30 \\
\hline $\begin{array}{l}\text { Ethnicity concentration (at } \\
\text { district level) }\end{array}$ & -0.05 & 0.10 & -0.20 & 0.08 & 0.12 & 0.08 \\
\hline nter & 0.04 & 0.08 & -0.21 & 0.07 & -0.06 & 0.08 \\
\hline East & -0.53 & 0.08 & -0.28 & 0.07 & -0.23 & 0.08 \\
\hline North & -0.39 & 0.08 & -0.03 & 0.08 & -0.04 & 0.08 \\
\hline $\mathrm{Nb}$. of migrants in hh (2005) & 0.24 & 0.05 & - & - & - & - \\
\hline Migration rate in the District & 1.30 & 0.31 & - & - & - & - \\
\hline Log Wealth DP. & 0 & 0.01 & - & - & - & - \\
\hline Intercept & -0.76 & 0.29 & 2.27 & 0.28 & 5.65 & 0.3 \\
\hline Loading fact. & -0.55 & 0.06 & 0.23 & 0.03 & 1 & - \\
\hline$\sigma$ & 1 & - & 0.24 & 0.02 & 0.49 & 0.03 \\
\hline
\end{tabular}

Notes: Head-MIG equals 1 if the current place of living of household is different from the place of household's head place of birth, that is when household's head has migrated permanently in the past (less than 11 years and more than two years). In the column of the likelihood migration, I have reported the parameters and they cannot be interpreted as a marginal effect. Only the sign is significant.

Source: Author's calculations based on UNPS. 
Figure A5: Actual and predicted distribution of agricultural production

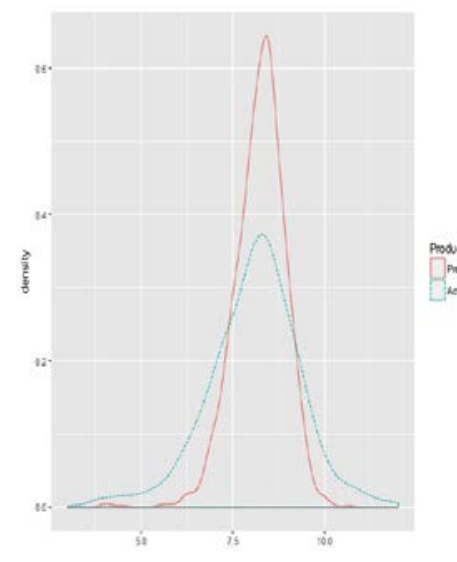

Period 1

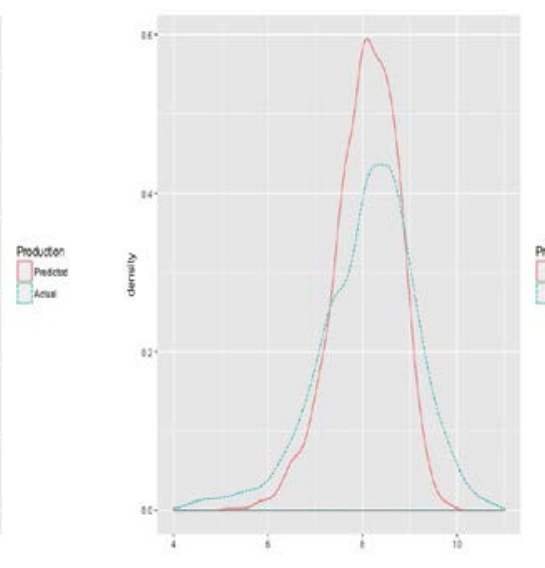

Period 2

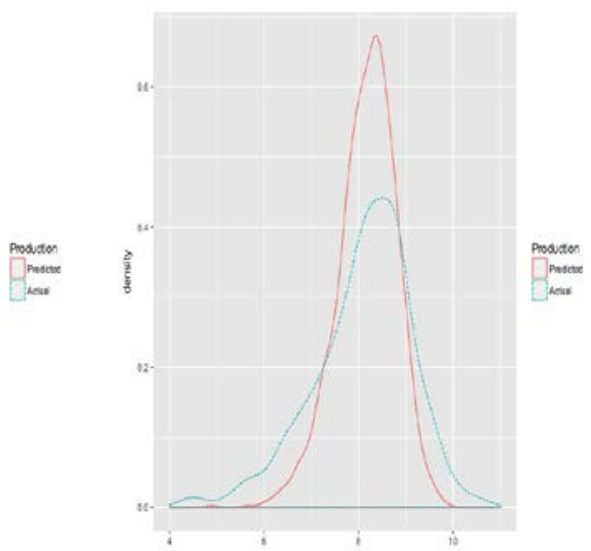

Period 3

Source: Author's illustration based on UNPS.

Figure A6. Density function of unobservables

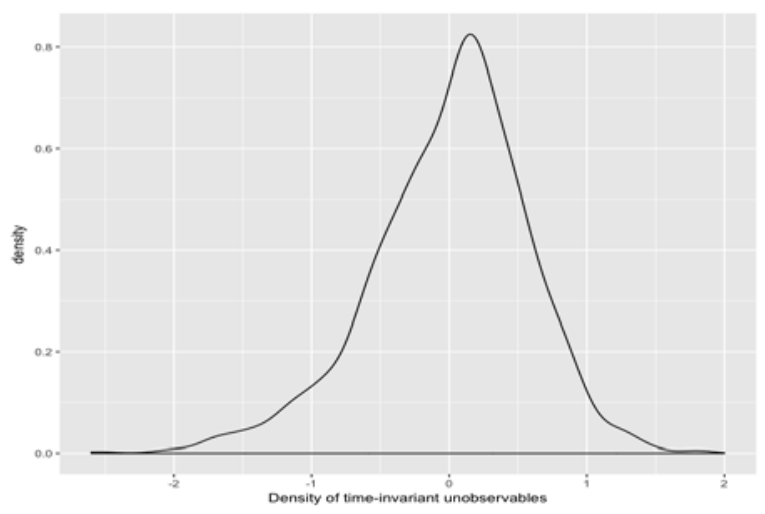

Source: Author's illustration based on UNPS.

Figure A7. Inverse demand of migration as a function of unobservables

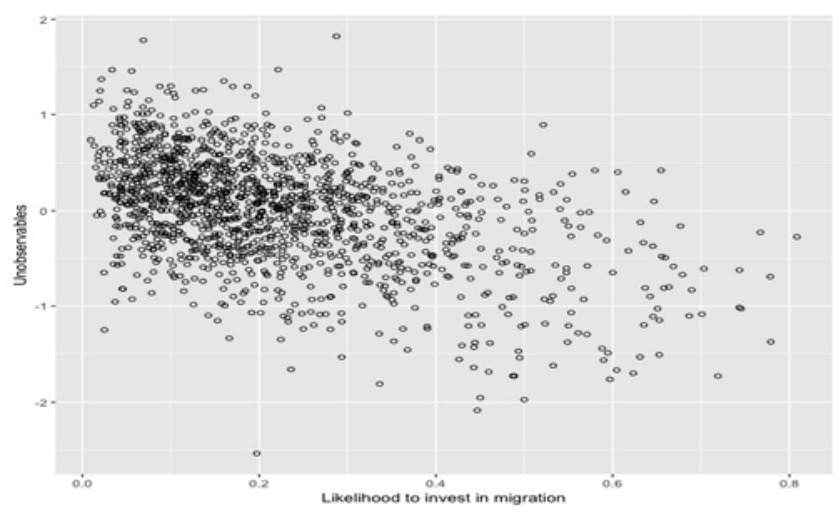

Source: Author's illustration based on UNPS. 
Figure A8. Heterogeneity of the effect by probability of participating in MIG

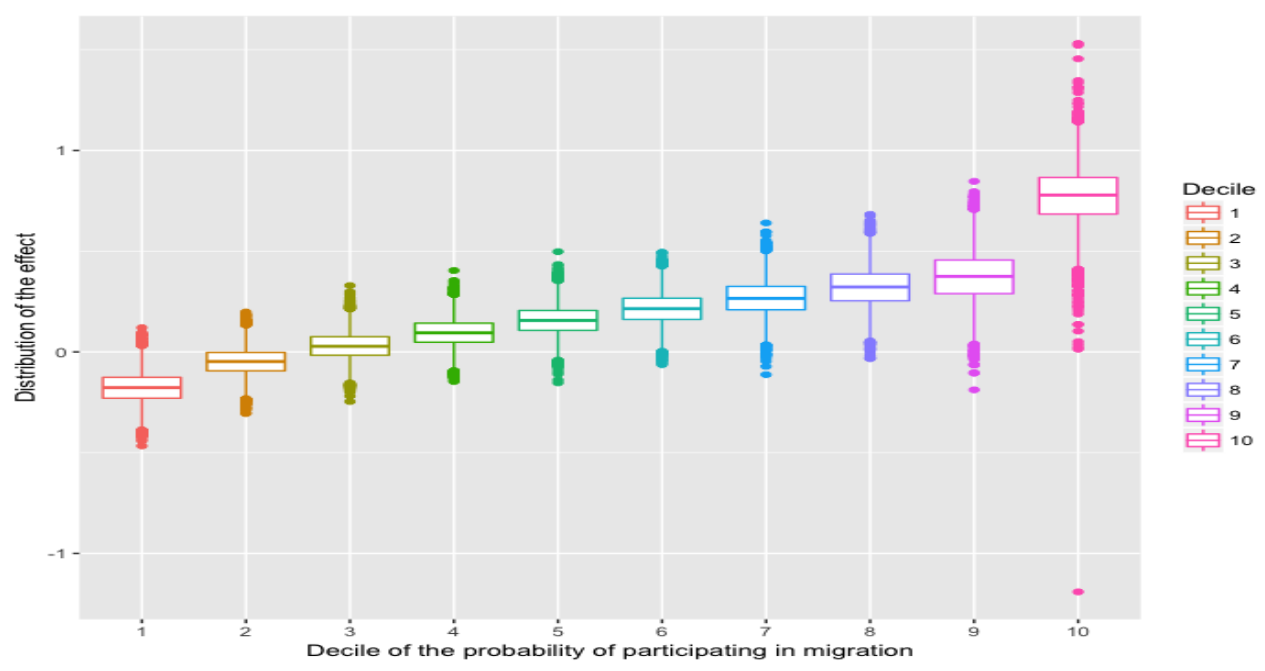

Source: Author's illustration based on UNPS.

Table A3: Percentage of households with positive return to migration

\begin{tabular}{lcccccc}
\hline & Central & Northern & Eastern & Western & $\begin{array}{c}\text { Num } \\
\text { crops }>13\end{array}$ & $\begin{array}{c}\text { Num } \\
\text { crops }<=13\end{array}$ \\
\hline Period 1 & 61.46 & 53.33 & 60.47 & 72.94 & 63.69 & 62.2 \\
Period 2 & 75 & 80 & 75.56 & 76.42 & 80.35 & 72.73 \\
Period 3 & 75.74 & 58.26 & 57.66 & 77.98 & 72.73 & 61.93 \\
\hline \multicolumn{7}{c}{ Non Migrants-sending HHs } \\
\hline Period 1 & 63.51 & 62.4 & 51.95 & 47.91 & 56.5 & 56.67 \\
Period 2 & 61.21 & 45.23 & 37.93 & 66.22 & 54.81 & 48.26 \\
Period 3 & 40.66 & 61.25 & 48.75 & 54.39 & 51 & 54.14 \\
\hline
\end{tabular}

Source: Author's illustration based on UNPS. 


\section{Appendix B: Sampling Algorithm}

1. Sample $\sigma$ from a Metropolis Hastings strategy. The posterior distribution is $h\left(\sigma \mid l_{o}, L_{o}, B, \theta,\left(\lambda_{1 i}\right)^{N}{ }_{i=1},\left(\lambda_{2 i}\right)^{N}{ }_{i=1},\left(\lambda_{3 i}\right)^{N}{ }_{i=1}\right)=f\left(\sigma \mid l_{o}, L_{0}\right) \times L\left(\operatorname{Prod}_{t}, L M_{t} \mid B, \sigma, \lambda, \theta\right)$ and $f(. \mid$.$) is a multivariate normal distribution of order two.$

To sample $\sigma$ from function $h(. \mid$.$) , Chib and Greenberg (1998) propose to sample \sigma$ from a multivariate-t distribution $q(\alpha, V)$ where $\alpha$ and $V$ are respectively the mode and the inverse of the negative of the hessian of $\log (b)$. Therefore, we move from $\sigma$ to $\sigma^{\prime}$ if :

$$
\min \left\{\frac{h\left(\sigma^{\prime} \mid l_{o}, L_{o}, B, \theta,\left(\lambda_{1 i}\right)^{N}{ }_{i=1},\left(\lambda_{2 i}\right)^{N}{ }_{i=1},\left(\lambda_{3 i}\right)^{N}{ }_{i=1}\right) q(\sigma \mid v, V)}{\left.h\left(\sigma \mid l_{o}, L_{o}, B, \theta,\left(\lambda_{1 i}\right)^{N}{ }_{i=1},\left(\lambda_{2 i}\right)^{N}{ }_{i=1}, \lambda_{3 i}\right)^{N}{ }_{i=1}\right) q\left(\sigma^{\prime} \mid v, V\right)}, 1\right\}=1
$$

This strategy enables to reach the convergence of $\sigma$ more rapidly.

2. Sample the unobserved component of the vector $H_{i t}^{*}=\left(M_{i t}^{*}, \operatorname{Prod}_{1 i t}^{*}, \operatorname{Prod}_{\text {oit }}^{*}\right), \forall t=$ $1,2,3$.

if $L M i t=1$ then sampled first $M U_{i t}^{*} \mid B, \sigma, \theta_{i}, \lambda_{1 i}, \lambda_{2 i}, \lambda_{3 i}$ from a normal distribution truncated to the interval ]0, $+\infty\left[\right.$. Instead, if $L M_{i t}=0$ then sampled $M U_{i t}^{*} \mid B, \sigma, \theta_{i}, \lambda_{1 i}, \lambda_{2 i}, \lambda_{3 i}$ from a normal distribution truncated to the interval $]+\infty, 0]$.

$\forall t \in\{1,2,3\}, i=1, \cdots, n$, sample either $\operatorname{Prod}_{1 i t}^{*}$ or $\operatorname{Prod}_{0 i t}^{*}$, independently from $i$ and $t$, from a normal distribution depending on whether $L M i t$ is equal to zero or one.

3. Sample the set of parameters $B \mid H_{i t}^{*}, b_{o}, B_{0}, \sigma,\left(\theta_{i}\right)_{i=1}^{N},\left(\lambda_{1 i}\right)_{i=1}^{N},\left(\lambda_{2 i}\right)_{i=1}^{N},\left(\lambda_{3 i}\right)_{i=1}^{N}$, from the normal distribution $\mathcal{N}(g, G)$, with

$g=G^{-1}\left(b_{0} B_{0}^{-1}+\sum_{i=1}^{N} R_{i}^{\prime} \Omega_{i}^{-1}\left(H_{i}-\Lambda \theta_{i}\right)\right) ; G=\left(B_{0}^{-1}+\sum_{i=1}^{N} R_{i}^{\prime} \Omega_{i}^{-1} R_{i}\right), \quad$ where $\quad \Omega=$ $\operatorname{diag}\left(\lambda_{i 1}, \lambda_{i 2}, \lambda_{i 3}\right) \otimes \operatorname{diag}\left(1, \sigma_{1}, \sigma_{0}\right)^{18}, H_{i}=\left(H_{i 1}, H_{i 2}, H_{i 3}\right)$

$R_{i}=\left[\begin{array}{c}\Delta_{i 1} \\ \Delta_{i 2} \\ \Delta_{i 3}\end{array}\right]$ is a matrix , with $\Delta_{i t}=\left[\begin{array}{cccc}Z_{i} & W_{i t} & 0 & 0 \\ Z_{i} & 0 & X_{1 i t} & 0 \\ Z_{i} & 0 & 0 & X_{0 i t}\end{array}\right]$ of dimension $(3 \times T, k) ; T=$ 3 and $k$ is the length of $B$ and $\Delta_{i}=[0,0,1,0,0,1,0,0,1]$.

4. Sample $\theta_{i} \mid H_{i t}, B, \sigma,\left(\lambda_{i 1}\right)_{i=1}^{N},\left(\lambda_{i 2}\right)_{i=1}^{N},\left(\lambda_{i 3}\right)_{i=1}^{N}$ from the normal distribution with mean $\mu_{\theta}^{i}=\sum_{\theta}^{i} D^{\prime} C^{-1} \bar{H}_{i}$ and $\sum_{\theta}^{i}=\left(\frac{1}{v_{0}}+D^{\prime} C^{-1} \lambda_{i}^{*} D\right)^{-1} . D=\left(\gamma, \gamma_{1}, 1\right)$ is the vector of loading factors $\quad, \quad \lambda_{i}^{*}=\sum_{i=1}^{N} \lambda_{i t}$ and $\bar{H}_{i}=\sum_{t=1}^{3} \lambda_{i t}\left(H_{i t}-\left[Z_{i} \beta+\right.\right.$ $\left.\left.X_{i t} \alpha_{m}, X_{1 i t} \alpha_{1}, X_{0 i t} \alpha_{0}\right]\right)$

5. Sample $\lambda_{i t} \mid H_{i t}, B, \sigma,\left(\theta_{i}\right)_{i=1}^{N}, \forall t=1,2,3 \quad$ from a gamma distribution $\mathcal{G}\left(\frac{\lambda_{0}+3}{2}, \frac{\lambda_{0}+H_{i t}^{\prime} C^{-1} \underline{H}_{i t}}{2}\right)$, with

\footnotetext{
$18 \operatorname{diag}(C)$ represents the diagonal matrix with the elements of vector $C$ on the diagonal and $A \otimes B$ stands for the kronecker product of $A$ and $B$.
} 


$$
\underline{H}_{i t}=H_{i t}-\left(\begin{array}{c}
Z_{i} \beta+X_{i t} \alpha_{m}+\theta_{i} \gamma \\
Z_{i} \beta^{1}+X_{1 i t} \alpha_{1}+\theta_{i} \gamma_{1} \\
Z_{i} \beta^{0}+X_{0 i t} \alpha_{0}+\theta_{i}
\end{array}\right)
$$

Complete the sampling procedure by repeating step 1 to step 5 .

\section{Some proofs}

We demonstrate now the parameters of the posterior distribution of $\theta_{i}$ in the simulation process. Given $H_{i t}, B, \sigma,\left(\lambda_{1 i}\right)_{i=1}^{N},\left(\lambda_{2 i}\right)_{i=1}^{N},\left(\lambda_{3 i}\right)_{i=1}^{N}$, we have from equation 4 that $H_{i t} \sim$ $\mathcal{N}\left(\Delta_{i t} A_{D \theta_{i}}, \lambda_{i t}^{-1} \Sigma\right)$ with $A$ be the vector of all parameters of the model except the loading factors.

Thereby, $\lambda_{i t}\left(H_{i t}-\Delta_{i t} A\right) \sim \mathcal{N}\left(D \theta_{i}, \lambda_{i t} \Sigma\right) \Leftrightarrow \sum_{t=1}^{3}\left[\lambda_{i t}\left(H_{i t}-\Delta_{i t} A\right)\right] \sim \mathcal{N}\left(\lambda_{i}^{*} D \theta_{i}, \lambda_{i}^{*} \Sigma\right), \lambda_{i}^{*}=$ $\sum_{t=1}^{3} \lambda_{i t}$

If we set $M_{i}=\sum_{t=1}^{3} \lambda_{i t}\left(H_{i t}-\Delta_{i t} A\right)$, the posterior distribution of $\theta_{i}$ following the Bayes rules is given by: $P\left(\theta_{i} \mid M_{i},.\right) \propto P\left(M_{i} \mid \theta_{i}\right) P\left(\theta_{i}\right)$. In the right hand side of the proportionate sign, both distributions are normal distributions meaning that they are proportionate to $\exp \left(-\frac{1}{2} Q\right)$, where $\theta_{i} \sim \mathcal{N}\left(0, v_{0}\right),{ }^{19}$ and

$$
\begin{aligned}
Q & =\left[M_{i}-\lambda_{i}^{*} D \theta_{i}\right]^{\prime}\left(\lambda_{i}^{*}\right)^{-1} \Sigma^{-1}\left[M_{i}-\lambda_{i}^{*} D \theta_{i}\right]+\theta_{i}^{\prime} v_{0} \theta_{i} \\
& =M_{i}^{\prime} \lambda_{i}^{*} \Sigma^{-1} M_{i}-M_{i}^{\prime}\left(\lambda_{i}^{*}\right)^{-1} \Sigma^{-1} \lambda_{i}^{*} D \theta_{i}-\theta_{i} D^{\prime} \Sigma^{-1} M_{i}+\theta_{i} D^{\prime} \Sigma^{-1} \lambda_{i}^{*} D \theta_{i}+\theta_{i} v_{0}^{-1} \theta_{i} \\
& =\theta_{i}\left[\lambda_{i}^{*} D^{\prime} \Sigma^{-1} D+v_{0}^{-1}\right] \theta_{i}-M_{i}^{\prime} \Sigma^{-1} D \theta_{i}-\theta_{i} D^{\prime} \Sigma^{-1} M_{i}+M_{i}^{\prime} \lambda_{i}^{*} \Sigma^{-1} M_{i} \\
& =\left[\theta_{i}-A K\right]^{\prime} A^{-1}\left[\theta_{i}-A K\right]+M_{i}^{\prime} \lambda_{i}^{*} \Sigma^{-1} M_{i} ; A^{-1}=\lambda_{i}^{*} D^{\prime} \Sigma^{-1} D+v_{0}^{-1}, K=D^{\prime} \Sigma^{-1} M_{i}
\end{aligned}
$$

The last term of the equality is independent from $\theta_{i}$ therefore, the posterior distribution $\theta_{i} \sim$ $\mathcal{N}(A K, A)$ which ends the demonstration with $A=\Sigma_{\theta}^{i}=\lambda_{i}^{*} D^{\prime} \Sigma^{-1} D+v_{0}^{-1}$ and $\mu_{\theta}^{i}=A K=$ $\Sigma_{\theta}^{i} D^{\prime} \Sigma^{-1} M_{i}$

\footnotetext{
${ }^{19}$ Since $\theta_{i}$ is a constant, it is equal to its transpose.
} 